\title{
THE INFLUENCE OF ANCESTRAL LIFEWAYS ON INDIVIDUAL ECONOMIC OUTCOMES IN SUB-SAHARAN AFRICA
}

\author{
Stelios Michalopoulos \\ Louis Putterman \\ David N. Weil \\ Working Paper 21907 \\ http://www.nber.org/papers/w21907 \\ NATIONAL BUREAU OF ECONOMIC RESEARCH \\ 1050 Massachusetts Avenue \\ Cambridge, MA 02138 \\ January 2016
}

We are grateful to Daniel Prinz, Devin Streur, Young Min Kim, Philip Trammell, and especially Yunan $\mathrm{Ji}$ for superlative research assistance. We are also grateful to Bill Easterly, Filipe Campante, Nico Voigtlaender and seminar participants at Cambridge University, Oxford University, University of Copenhagen and to participants at the "DeepRooted Factors in Comparative Economic Development" at Brown University, the CESifo workshop on Demographic Change and Long Run Development, the BCEP conference at Berkeley, the NYU DRI 2015 Annual Conference and the NBER Political Economy group for helpful comments. The views expressed herein are those of the authors and do not necessarily reflect the views of the National Bureau of Economic Research.

NBER working papers are circulated for discussion and comment purposes. They have not been peerreviewed or been subject to the review by the NBER Board of Directors that accompanies official NBER publications.

(C) 2016 by Stelios Michalopoulos, Louis Putterman, and David N. Weil. All rights reserved. Short sections of text, not to exceed two paragraphs, may be quoted without explicit permission provided that full credit, including $(\mathcal{C}$ notice, is given to the source. 
The Influence of Ancestral Lifeways on Individual Economic Outcomes in Sub-Saharan Africa Stelios Michalopoulos, Louis Putterman, and David N. Weil

NBER Working Paper No. 21907

January 2016, Revised June 2016

JEL No. O0,O1,O13,O40,Z00,Z1

\begin{abstract}
$\underline{\text { ABSTRACT }}$ power, may contribute to these divergent outcomes.

Stelios Michalopoulos

Brown University

Department of Economics

64 Waterman Street

Providence, RI 02912

and NBER

smichalo@brown.edu

Louis Putterman

Department of Economics

Brown University

64 Waterman Street

Providence, RI 02912

Louis_Putterman@brown.edu

David N. Weil

Department of Economics

Box B

Brown University

Providence, RI 02912

and NBER

david_weil@brown.edu
\end{abstract}

Does a person's historical lineage influence his or her current economic status? Motivated by a large literature in social sciences stressing the effect of an early transition to agriculture on current economic performance at the level of countries, we examine the relative contemporary status of individuals as a function of how much their ancestors relied on agriculture during the preindustrial era. We focus on Africa, where by combining anthropological records of groups with individuallevel survey data we can explore the effect of the historical lifeways of one's forefathers. Within enumeration areas and occupational groups, we find that individuals from ethnicities that derived a larger share of subsistence from agriculture in the precolonial era are today more educated and wealthy. A tentative exploration of channels suggests that differences in attitudes and beliefs as well as differential treatment by others, including differential political 


\section{Introduction}

Economists generally agree that history matters in explaining variations in the standards of living among people. But what aspects of history should we be looking at? Two of the most important are the history of the place where the individual lives and the history of his or her own lineage.

Of these two branches, the study of how historical events in a given place shape economic outcomes is the better developed. In large part, this is because it is relatively easy to map the locations of historical events to modern-day territories. If we know that something happened in one place and not another -- for example, on one side of a border but not the other -- we can compare contemporary outcomes of these two places, and thus learn about the role of whatever it was that differed. This strategy has been particularly fruitful in examining the role of institutions, which have the nice property of tending to stay put in physical locations. ${ }^{1}$ A slight variant on this literature on persistence in places allows for movements of large groups of people from one place to another, recognizing that when these large-scale migrations take place, people may bring with them much of whatever it is -- culture, institutions, etc. -- that was found in their place of origin. ${ }^{2}$

Among the various place-based determinants of comparative development, the transition to agriculture is often cited as being of paramount importance in fostering the development of modern urban civilizations. This idea is at the heart of a venerable line of research among anthropologists and historians embracing social evolutionary schema. Among economists Hibbs and Olsson (2004), Putterman (2008) and Borcan et al. (2014) establish empirically a positive influence of early agricultural transition on state formation and contemporary incomes across countries. This place-centered perspective on history points naturally toward thinking about aggregate or average incomes in a particular country or region in the modern world.

The other approach to quantifying the role of history looks at heterogeneity in outcomes within a population. The focus here is on the lineage of an individual, and how this contributes to his or her relative economic standing and cultural attributes today (Fenske, 2013; Alesina, Giuliano and Nunn, 2014). Over periods of a few generations, the effects of one's lineage on current outcomes is addressed under the heading of intergenerational mobility. However, economists are increasingly realizing that there are elements of lineage that are important beyond what can be understood from, say, a one generational transition matrix. Recent attempts to lengthen the intergenerational horizon include works by Clark (2015) and Guell et al. (2015) who use surnames to track family-level economic performance over several generations, finding that intergenerational mobility is rather low.

\footnotetext{
${ }^{1}$ Acemoglu et al. (2001, 2002), Banerjee and lyer (2005), Iyer (2010), Dell (2012), Michalopoulos and Papaioannou $(2013,2014)$.

2 Putterman and Weil (2010), Abramitzky et al. (2014).
} 
In this paper, our goal is to apply this second, lineage-based approach, in a context where we can link lineages all the way back to variation in ancestral "lifeways," that is, forms of economic support before the advent of the modern industrial era. In particular, the question we ask is whether tracing one's lineage to predominantly farming communities in the pre-industrial period is beneficial in the modern era, specifically the world of urban and rural sub-Saharan Africa. Notably, since we are looking at variation in individual economic outcomes within specific locations, the stories about how agricultural history shapes place-based differences in economic performance, discussed above, are less applicable in our framework.

A well-known social evolutionary approach holds that human societies progressed from hunter-gatherer origins to industrial modernity via the development of sedentary agriculture and its maturation into state-level, partially urban societies. Although there is no evidence that pastoralism predated agriculture chronologically, its less sedentary character often leads to its characterization as if reflecting a regression backwards from settled society. As Krätli (2001) writes, "At the core of the public representation of pastoralism is the idea that 'pastoralism' and 'modern life' are mutually exclusive, as two successive stages of human development in a unique line that goes from nature to civilisation, passing from sedentary life and agriculture. This frame offers no ground on which pastoralism and modern world could meet: one being thought to begin where the other is supposed to end." This view of herders as less civilized than agriculturalists, or as a dead end branch line off the main path from agriculture to civilization, echoes millennia-old Chinese, Persian, and Egyptian views of steppe and desert nomads. Motivated by this sweeping narrative our paper explores whether a similar evolutionary approach can also be traced in the current economic outcomes of descendants of groups that practised different subsistence patterns during the pre-industrial era. Our study is the first of which we are aware which explores the impact of economic culture, as identified by the primary source of subsistence, at the individual level. ${ }^{3}$

We study Africa for several reasons. First, it is a place where the transition away from historical lifeways took place only recently. On the eve of the "Scramble for Africa" in the late nineteenth century, the continent was replete with examples of almost every kind of pre-industrial subsistence economy, from hunter-gatherers, to nomadic pastoralists, to shifting and intensive agriculturalists. Second, Africa presents a setting in which it is relatively easy to match individuals with the economic lifeway of their pre-industrial ancestors. In brief, lifeways can be associated with ethnic groups, and given the rather limited mating across ethnic lines, modern individuals can usually be identified with a single tribe, and thus a particular historical lifeway. ${ }^{4}$ Finally, in the modern African setting, we can identify individuals with different ancestral lifeways

\footnotetext{
${ }^{3}$ For the role of economic culture (as reflected in the dependence on fishing) on regional economic performance, see Dalgaard et al (2015).

${ }^{4}$ The limited degree of interethnic marriages is evident in our sample of households surveyed at the turn of the 21st century. Within an average household in the Demographic and Health Surveys, there is a $71 \%$ probability that the ethnic identity of the wife is identical to that of her husband, despite the considerable ethnic heterogeneity of many of today's urban centers. In absence of historical data, we believe that intermarriage rates were far lower in previous generations.
} 
living in the same location, thus allowing us to study lineage-based historical effects in isolation, that is, purged from the effects of the place-based history.

The channels by which lineage -- and in particular the pre-modern economic lifeways of an individual's ancestors -- can affect modern outcomes are not the same as those channels that would be operative at the level of locations. Most significantly, institutions are generally associated with places, and thus are unlikely to explain heterogeneity of outcomes within a region. Hence, culture is a natural suspect, as it is something that can vary among individuals in a given location based on their lineage. As we discuss below, there are particular cultural traits associated with increased dependence on agriculture that one would expect to yield differential benefits in a modern economic setting. Our approach of identifying the effect of culture on outcomes at the individual level by focusing on people with different origins living in the same place follows what Fernandez (2011) calls the "epidemiological approach" to studying culture. This has been implemented using international migrants to study culture's effect on fertility (Fernandez and Fogli, 2009) and saving rates (Caroll, Rhee, and Rhee, 1994), among other things.

Pursuing our inquiry requires being able to associate individuals in a modern data set with historical characteristics of the groups from which they are descended. The Demographic and Health Surveys on which we mostly rely contain data on the ethnicity of individuals. We match this data with information from Murdock's (1967) Ethnographic Atlas on historical characteristics of ethnic groups as well as information from Murdock (1959) on the geographical regions historically inhabited by these ethnicities. Matching these two data sets required the construction of a concordance of ethnicities, the details of which are discussed below. We expect that this concordance will have great usefulness beyond the current study.

Our main finding is that the higher the share of their subsistence a person's ancestors obtained from agriculture, the higher are his or her education and wealth levels today. This result holds not only comparing the descendants of pastoralists to the descendants of agriculturalists, but also comparing the descendants of non-pastoralist groups that varied in the degree to which they relied on agriculture. Importantly, this pattern continues to hold even when we restrict our attention to individuals living outside their group's ancestral homelands, to residents within urban places, and to individuals engaged in occupations other than agriculture and animal husbandry.

The rest of this paper is structured as follows. Section 2 discusses the related literature on the historical determinants of modern economic and political outcomes, with an emphasis on Africa. In Section 3, we introduce the ethnicity data from the DHS that we use, and discuss the matching of modern ethnicity to historical groups, their ancestral locations, and pre-colonial characteristics. In Section 4, we describe the data on the historical means of subsistence of African groups and estimate empirical models linking education and wealth to the ancestral lifeway characteristics of an individual's group, controlling for the current location of residence. We experiment with splitting the sample by occupation and urban/rural location, with inclusion of 
enumeration area fixed effects, and also assess the role of selection into migration. In Section 5, we explore the determinants of ancestral lifeways themselves, in particular, the degree to which dependence on agriculture is a function of land's agricultural quality. We then use land quality as an instrument for ancestral agricultural dependence in our basic regression setting, finding broadly similar estimates. In Section 6, we investigate whether the identified pattern is robust to exploiting variation in the mode of subsistence within linguistic or ethnic families. In Section 7 , we examine the potential channels at work, investigating how the inclusion of pre-colonial and colonial-era variables influences our basic results. We also report exercises exploring the roles of differential treatment by the central government, as well as whether personality traits related to proclivity to violence, impatience, and cooperation, might help explain the less favorable outcomes of descendants of communities relying less on agriculture in the pre-colonial era. We bring to bear data from the Afrobarometer surveys, to supplement the DHS. While these exercises yield some suggestive results, we emphasize their provisional nature and secondary importance relative to our core finding that pre-modern lifeway is a robust correlate of economic outcomes generations later. Section 8 concludes.

\section{Related Literature}

A growing body of work examines the historical origins and political economy of African development. Broadly speaking the main arguments that have been proposed in this literature refer to three different periods in African history. In reverse chronological order, the first category includes an influential body of research that stresses how the institutions established by European powers during colonization persisted after independence and continue to shape contemporary economic performance (e.g., La Porta et al. (1997, 1998); Acemoglu et al. (2001, 2002), Michalopoulos and Papaioannou (2014)). The second set of studies focuses on events that took place during the colonial period itself. Huillery (2009), Berger (2009), and Arbesu (2011), for example, quantify the long-run effects of colonial investments and tax collection systems whereas recent works shed light on the negative effects of the improper colonial border design during the Scramble for Africa. ${ }^{5}$ Finally, several recent studies highlight the persistent legacy of the pre-colonial era. Nunn (2008) and Nunn and Wantchekon (2011), for example, stress the role of slave trades while Michalopoulos and Papaioannou (2013) demonstrate the beneficial role of ethnic political centralization on regional African development.

Our study belongs to the latter strand by establishing that descendants of predominantly agricultural groups today outperform economically individuals from groups of different pre-colonial occupational backgrounds. This finding contributes to our understanding of the legacy of ethnicity in Africa and sheds light on the sources of ethnic inequality, a feature that has been linked to underdevelopment, see Alesina, Michalopoulos and Papaioannou (2016).

More generally, our work relates to the literature on the cultural origins of comparative

${ }^{5}$ Englebert, Tarango, and Carter (2002), and Michalopoulos and Papaioannou (forthcoming). 
development, adding to a vibrant body of research that examines the within-country impact of various historical legacies on economic performance. By utilizing individual-level variation we overcome some of the identification problems inherent to cross-country or cross-regional analyses. First, it allows us to quantify how much of the individual-level variation in economic outcomes may be attributed to one's ethnic identity. Second, we can account for location-specific traits. This is feasible because we observe people from different ethnic groups residing in the same enumeration areas.

The introduction of location fixed effects is crucial, since it allows us to absorb characteristics related to the geographic, ecological and institutional environment of a given region that recent studies have highlighted as important determinants of regional African development. ${ }^{6}$ Moreover, it allows us to uncover the importance of portable ethnic-specific traits whose influence is not limited to the ancestral homeland of a given group. This methodology is similar to Nunn and Wantchekon (2011), who investigate the impact of slavery on individual trust among respondents residing outside their ethnic enclaves.

Our finding that descendants of groups that in the pre-colonial era derived a larger share of subsistence from agriculture are today more educated and more wealthy brings to the foreground the persistent role of traits vertically transmitted within groups over time. In this respect, our study contributes to an emerging body of work that emphasizes the importance of cultural norms, historical persistence, and human and geographic traits for comparative development (see Diamond (1997), Landes (1998), Guiso, Sapienza, and Zingales (2006), Easterly and Levine (1997, 2012), Spolaore and Wacziarg (2009), Putterman and Weil (2010), Ashraf and Galor (2013), and Michalopoulos, Naghavi, and Prarolo (2012) among others).

\section{Ethnicity and Modern Outcomes}

\subsection{Ethnicity Data}

Our starting point is data from the Demographic and Health Surveys (DHS) for 26 countries in which an ethnicity variable was collected as part of the survey. We use the most recent DHS wave for which both ethnicity information and location coordinates are available. This reduces the sample to 21 countries since for 5 out of 26 countries we do not have coordinate information from the DHS. The sample size with information on both ethnicity and enumeration area coordinates ranges from 3,040 individuals for the Ivory Coast to 48,871 for Nigeria, totalling 337,382 respondents. In our final DHS sample, there are 492 ethnicity-country groups, where the same ethnicity appearing in two different countries is counted as two different groups. ${ }^{7}$

\footnotetext{
${ }^{6}$ Alsan (2015), Fenske (2013).

7 The survey rounds in the respective countries are: BF6(Burkina Faso), BJ4(Benin), CD5(Congo Democratic Republic), CF3(Central African Republic), CM4(Cameroon), ET6(Ethiopia), GH5(Ghana), GN4(Guinea), (Cl3) Ivory Coast, KE5(Kenya), ML5(Mali), MW5(Malawi), MZ6(Mozambique), NG5(Nigeria), NI3(Niger), NM4(Namibia), SL5(Sierra Leone), SN6(Senegal), TG4(Togo), UG6(Uganda),
} 


\subsubsection{Matching Modern Ethnicities to Ancestral Groups, Historical Locations, and Group-Specific Pre-Colonial Traits}

The information on tribal pre-colonial traits comes from Murdock's (1967) Ethnographic Atlas while the spatial information on the homeland of a group in the beginning of the colonial era comes from Murdock's (1959) Map. Note that these two lists of groups do not always coincide. So, we linked the ethnicity as reported by each respondent in the DHS to both Murdock's (1967) list and Murdock's (1959) Map. Whenever possible we used the concordance constructed by Fenske (2013) and Michalopoulos and Papaioannou (2013) to associate the groups in Murdock's Map (1959) to the groups in Murdock's Atlas (1967).

A total of 287,433 individuals were matched to a Murdock Atlas group and assigned characteristics of the corresponding ethnic group in the Ethnographic Atlas. A slightly larger number, 292,942, were matched to groups included in the Murdock Map.

Our matching procedure was as follows. We constructed a series of ten possible methods for matching ethnicities in the DHS to ethnicities in one of the Murdock datasets. These methods were ordered from best to worst in terms of our assessment of their likely accuracy. We then proceeded down the list, using for each DHS ethnicity the first method for which we were able to achieve a match. Matching was done separately for the ethnicities included in the Atlas and Map, respectively. In the text below we describe the most important methods. In Appendix Table 1 we describe all ten methods and give the fractions of cases matched using each one.

The method at the top of our list was "direct match," in which the same name was used in the DHS and the Murdock source. We were able to directly match $58.7 \%$ of observations to Atlas ethnicities and $67.0 \%$ to the ethnicities on the Murdock Map. The second method on our list was "Afrobarometer match", in which we applied to the ethnicity names that appear in the DHS the concordance constructed by Nunn and Wantchekon (2011) from ethnicity names that appear in the Afrobarometer Round 3 dataset to ethnicities that appear in the Murdock dataset. This matched a further $4.5 \%$ of observations to Atlas ethnicities and $10.0 \%$ of observations to the Map's ethnicities. The next three methods used data on alternate ethnicity names from the Ethnologue or Joshua Project. The third method applied to cases where the DHS and Murdock names were listed as alternates; the fourth where a name that appeared in the Murdock source is listed as a superset of the ethnicity that appears in the DHS; and the fifth where the name that appears in the DHS is listed as a subset of the ethnicity in the Murdock data. Together, these three methods matched $19.1 \%$ of observations to Atlas ethnicities and $13.2 \%$ to Map ethnicities.

and ZM5(Zambia). 


\subsubsection{Movers and Average Distance Moved}

As described above, much of our interest in this paper is with the aspects of human capital (broadly defined) that persist over generations and are portable across locations. Further, we are interested in aspects of culture that have their origins in the conditions of particular geographic locations. To the extent that people live in the regions traditionally associated with their kin, it would not be possible to separately identify the effect of tribal characteristics from geographical characteristics. Thus we have a particular interest in individuals who live outside the territory associated with their group of origin. We follow Nunn and Wantchekon (2011) in calling such individuals "movers," even though they may not have moved in their own lifetimes. A better name for such individuals might be "non-autochthonous."

The DHS reports coordinate information for a person's current residence. We can thus classify individuals as living inside or outside their ancestral homeland. For those living outside of their homeland, we generated a variable measuring distance to their homeland. Specifically, this is the distance from the coordinates of an individual's current residence reported in the DHS survey to the nearest border of his/her ancestral homeland (Murdock's map). ${ }^{9}$

In the DHS data, $40 \%$ of individuals currently live within the boundaries of their ancestral homelands. Of those who do not, 12\% live more than 500 kilometers, 36\% between 100 and 500 kilometers, $43 \%$ between 10 and 100 kilometers, and $9 \%$ within 10 kilometers of the border. Given the imprecise nature of the borders in the Murdock map, the fact that ethnic group locations may have some overlap and that DHS coordinates are perturbed by 5 or 10 kilometers, we are reluctant to assume that a member of this last group are in fact living away from their ancestral lands. Hence, we do not include them in our definition of "movers" in the empirical exercises below. Appendix Table 2 gives summary statistics for our DHS sample as a whole.

\subsection{Ethnicity and Modern Outcomes}

We focus on two outcomes: education and wealth. Education is coded on a scale of 0-5, with categories "no education", "incomplete primary", "complete primary", "incomplete secondary", "complete secondary", and "higher." Wealth is a measure of household wealth, and is coded on a 1-5 scale that divides the sampled population within a country into quintiles of household wealth for that specific country. Rutstein and Johnson (2004) provide a detailed description of

\footnotetext{
${ }^{8}$ The DHS reports whether an individual has moved in his/her lifetime for a subset of respondents. This question does not distinguish between people that moved out of their homeland or from some other location within their homeland.

${ }^{9}$ Out of the 285,155 respondents, we have distance to ancestral homeland for 258,284 . In the remaining cases, we have matched directly the DHS ethnicity of the respondent to an Atlas group so we have information on its pre-colonial traits but we could not match this Atlas group to an ethnic group on the Murdock Map. For cases where an individual is matched to more than one ancestral homeland, the nearest homeland was picked to compute this distance.
} 
the construction of this index. ${ }^{10}$ The raw correlation between education and wealth in the full sample is 0.45 and the correlations of these variables with an urban indicator are 0.36 and 0.60 , respectively.

Before turning to the role played by ancestral ethnic characteristics, we explore the predictive power of ethnicity more generally in our data. Table 1 reports $\mathrm{R}^{2}$ 's from regressions of our education and wealth measures on different sets of dummy variables; namely, country fixed effects, current ethnic homeland fixed effects, and ethnic identity fixed effects. The ethnic homeland fixed effects are dummy variables corresponding to the current tribal location of the individual according to the Murdock map. We also report the $\mathrm{R}^{2}$ from combining different groups of dummy variables to gauge the additional explanatory power of different sets of dummies.

The regressions show, first of all, the role of ethnicity in determining outcomes. For example, once country fixed effects are included in the regression, adding country-ethnicity constants raises the $\mathrm{R}^{2}$ for education from .159 to .282 , and for wealth from .013 to .164 (results for movers are slightly larger). ${ }^{11}$ Current country-ethnic homeland has more predictive power than does ethnic affiliation: for education, the difference is about 2 percentage points, while for wealth the difference is 8.5 percentage points. However, what is more important for our analysis is that even when dummies for current country-ethnic location are included in the regression, there is still an improvement in fit (of about 2.3 - 4.2 percentage points in all the specifications) by adding dummies for the ethnic identity of the respondent.

\section{The Influence of Ancestral Characteristics on Modern Outcomes}

We now turn to our main line of inquiry, which is to examine how historical characteristics of an individual's group are related to her current outcomes. We begin by discussing the main historical measure of interest, which is the group's mode of pre-colonial subsistence. We then relate contemporary individual economic status to the historical mode of subsistence of one's ancestors, and discuss the robustness of our findings.

\subsection{Historical Mode of Subsistence}

Having established a match between current ethnic identity and historical ethnicity, we can use the latter's characteristics as described in Murdock's Ethnographic Atlas. The central historical characteristic on which we focus is an ethnic group's pre-colonial mode of subsistence.

\footnotetext{
${ }^{10}$ The DHS wealth index is composed taking into account consumer durables, electricity, toilet facilities, source of drinking water, dwelling characteristics, and some country-specific attributes such as whether there is a domestic servant, for example. The measure is derived by the DHS using principal component analysis to assign indicator weights resulting in a composite standardized index for each country.

${ }^{11}$ Note that the $\mathrm{R}^{2}$ for the country-fixed-effects regression on wealth is almost to zero because wealth is standardized by country.
} 
As mentioned in our introduction, proponents of an evolutionary framework to technological, social and economic development, including Sahlins and Service (1960), Service (1971), and Johnson and Earle (2000), see rough continua of social complexity, scale and degree of centralization of polity, and level of technological sophistication, running from "band-level" societies subsisting on hunting and gathering to "state-level" societies subsisting on agriculture and ultimately supporting the emergence of urban centers with more complex divisions of labor. Although usually denying uniformity of path along such a continuum, lifeway steps from foraging to shifting cultivation and horticulture and onwards to settled, plough-using agriculture are frequently observed markers in this literature. The independent emergence of agriculture, its gradual intensification, and the rise of cities and large-scale states in distant and largely independent regions including the Near East, China, and Mesoamerica, suggests a natural progression within which steps can be skipped, if at all, only when there are nearby models being copied or imposed. Absent such borrowing opportunities, cities and states will emerge only after a sufficient period of agricultural intensification and population growth.

Within Africa agriculture was spread to the regions of central and southern Africa that contain modern countries such as Angola, D.R. Congo, Uganda, Kenya, Zimbabwe, and South Africa by farming societies originally located around modern-day Nigeria and Cameroon. Linguistic and archeological evidence supports the view that before the arrival of agriculture--about 3,000 years ago in Congo, 1,800 years ago in Zambia and 1,000 years ago in Botswana--these regions were inhabited by considerably less populous foraging populations of whom today's San and Pygmy groups are probably remnants (Oliver and Fage, 1990; Diamond, 1997; Diamond and Bellwood, 2005).

While not a tenet of the social evolutionists in itself, the tendency towards gradualism of progressions just noted may have a correlate in cases of contact between cultures at different stages of development: that when an industrial society offers "modernizing" opportunities to pre-industrial societies via forms of contact including colonization, trade, and development assistance programs, the receiving cultures may be able to absorb the new opportunities more readily if situated on the agrarian side of the pre-industrial continuum than if reliant upon horticulture and, even more so, foraging. Reasons for greater ease of adoption by agrarian societies may include differences in work habits (longer and more intensive work hours are more the norm in agrarian than in foraging societies [Sahlins, 1972]), and cultural norms associated with large-scale, hierarchical and extra-familial organizations (such as states and corporations). ${ }^{12}$ Of course, it may also be the case that "bearers of civilization" such as the European missionaries who transmitted literacy and other technologies to many of the countries concerned, had subjective biases about agriculturalists being more promising recipients of their message, and that this in itself skewed transmission towards members of agricultural groups.

Richerson et al. (2000) note the challenge of situating pastoralism within evolutionary

12 The idea that modern organizational forms are more easily taken up by those on the agrarian state than those on the foraging band end of the social evolutionary continuum is discussed at length by Putterman (2000). 
frameworks of the kind discussed here. Because they rely primarily on domesticated rather than hunted animals, pastoralists must be located on the same side of the Neolithic divide as members of agricultural societies. Their historical emergence is thus viewed as one of specialization following the onset of both plant and animal domestication, not an independent and early branching from foraging. While not therefore representing a stage lying between foraging and agriculture on a temporal continuum, pastoralists nonetheless resemble foragers in their less settled way of life. Richerson et al. (2000) highlight the more exaggerated sexual division of labor, tighter bonds to immediate family, frequently observed propensity towards violence, and more contested nature of property - "herd animals are relatively easy to rustle, and pastoralists everywhere are in the habit of stealing from each other" - as features that might make adoption of modern norms and practices more challenging for members of pastoral than of agrarian societies.

Based on these considerations, it seems reasonable to treat pastoral societies as occupying a place intermediate between agrarian and foraging societies in terms of proximity of lifeway to that of the populous agrarian civilizations. If this is so, then the idea of more rapid adoption of modern social and physical technologies by those closer to the urban industrial end of the foraging to agrarian civilization continuum should imply that those from agricultural societies will be found to have achieved better recent economic outcomes, on average, than those from pastoral ones, who would in turn have achieved better outcomes than those from societies practicing foraging when incorporated into colonial and postcolonial states.

It is perhaps important to note that, notwithstanding the narrative among anthropologists regarding the apparent relationship between state centralization and agricultural intensification worldwide, this nexus in the context of Africa is much more nuanced. In fact, across all African groups (in Murdock's Atlas) the correlation between dependence on agriculture and group's political centralization is negligible (0.05) whereas the correlation between centralization and the share of subsistence derived from pastoralism is somewhat larger but still very small (0.12). This suggests that the origins of centralization in Africa are not directly related to the underlying mode of subsistence or pre-colonial population densities. This pattern is also shown by Osafo-Kwaako and Robinson (2013), suggesting that our measures of pre-colonial mode of subsistence do not reflect the legacy of political centralization of these groups. Below we will formally explore whether the influence of ancestral modes of subsistence on individual outcomes within a village are driven by variation in other pre-colonial traits.

The Ethnographic Atlas lists five activities--gathering, hunting, fishing, animal husbandry, and agriculture--and classifies the share of subsistence obtained from each into 9 broad bands: 0 $5 \%, 6-15 \%, 16-25 \%, \ldots, 85-100 \%$. With the exception of 17 individuals belonging to a single ethnic group, the Mbuti, in D.R.C. and located in the same enumeration area, our sample contains no other individuals from groups that pre-colonially relied primarily on hunting and gathering, activities that instead appear in our data as supplementary subsistence sources for groups mainly engaged in agriculture. The Atlas also distinguishes between "extensive agriculture" and "intensive agriculture." However, explorations making use of that division found 
no clear distinctions between these two kinds of groups (see Appendix Table 3 below). To focus on potential differences in outcomes attributable to differences in the extent of ancestral groups' reliance on agriculture we count reported subsistence shares from both extensive and intensive agriculture as belonging to a single activity, farming.

Of the 285,155 individuals in our sample for which Murdock includes information on pre-colonial subsistence, $84.2 \%$ are members of ethnic groups for which agriculture was the most important source of subsistence pre-colonially, according to the Atlas, $7.4 \%$ come from groups for which animal husbandry was most important (pastoralists), $8.4 \%$ from groups for which agriculture and animal husbandry $(7.5 \%)$ or agriculture and fishing $(0.9 \%)$ were equally important, and none other than the seventeen Mbuti being from a group for which hunting and gathering were leading activities in their own right. Assigning the Atlas's subsistence share bands the consecutive integer values 1 (for $0-5 \%$ ), 2 (for $6-15 \%$ ), etc., we find that individuals from groups in which agriculture was most important according to the Ethnographic Atlas score an average of 6.3 (standard deviation of 1.0), implying that agriculture provided about $60 \%$ of overall subsistence. Animal husbandry, hunting, gathering and fishing together account for the remaining roughly $40 \%$ of the traditional subsistence of agricultural groups, with each of the last three categories providing less than $5 \%$ of subsistence on average, although fishing, in particular, accounts for up to $35 \%$ of subsistence for a few small groups.

Individuals from groups for which pastoralism was the most important activity according to the Ethnographic Atlas have virtually the same average band score for their leading activity (6.3, with a standard deviation of 1.6). Among these groups, the mean of the agriculture variable is 2.3 (standard deviation of 1.6). In our regression analysis, we treat the share of subsistence derived from pastoralism as the default activity and use as our focal independent variable the integer indicator for the degree of traditional reliance on agriculture, with the summed integer scores for reliance on hunting, gathering and fishing by the individual's ethnic group among our controls. In interpreting our regression coefficients, a convenient standard is to consider the difference in reliance on agriculture between groups reporting agriculture as their most important means of subsistence and those reporting that pastoralism plays this role. The difference is 4 points on the scale described above.

\subsection{Benchmark Regressions}

The first panel of Table 2 shows our basic results. We regress our education and wealth measures on the subsistence shares of agriculture and hunt/gather/fish in an individual's ancestral group. The omitted category is the share of pre-colonial subsistence derived from pastoralism. In all specifications we include controls for age and age-squared, a female dummy and an indicator of whether the respondent resides outside her ancestral homeland (referred to as "simple controls"). In columns 1 (for education) and 5 (for wealth) we include country fixed effects. The coefficient on agriculture is positive and significant, implying that the more of its subsistence an individual's ancestral group obtained from working the land, as opposed to 
herding animals, the more educated and the wealthier he or she is today. This accords with the conjecture that agriculturalists and their descendants have on average obtained more education, adopted more advanced technologies, and entered more modern sectors of their economies than pastoralists and their lineages.

In this regression, as well as most of the specifications in this table, the coefficient on the hunt/gather/fish measure is also positive and significant. If this were an indication that descendants of hunter-gatherers such as the Twa of Rwanda, the Kung-San of Botswana and Namibia, or the Mbuti of the Congo, have also modernized more rapidly than their pastoralist counterparts, it would severely challenge the social evolutionist logic discussed above. Recall, however, that hunting and gathering are primary sources of subsistence for the ancestors of only a handful of individuals in our sample. It is common to see hunting and gathering account for a minor share of traditional subsistence in primarily agricultural groups, according to our sources, but only fishing is ever assigned parity with the lead subsistence source, and only in a few small groups accounting for under 2,500 observations. Given the supplemental rather than primary role of these activities, positive effects of a larger subsistence share from hunting, gathering and fishing are thus more plausibly interpreted as suggesting lasting benefits of an ancestral group's occupation of an enriched environment, rather than signaling that the lifeway of true hunter-gatherers conferred long-run advantages in its own right.

To make this point more precise in Appendix Table 3 we use as explanatory variables instead of the shares from each mode of subsistence, indicator variables reflecting whether a respondent's ancestral group was mostly agricultural (distinguishing between mostly intensive, mostly extensive and mostly unknown agriculture), or had two equally important subsistence sources or was mostly depending on gather/hunt/fish (the omitted category being mostly pastoral). Using this categorization indicates that descendants of hunter and gatherers clearly underperform vis $a$ vis the other subsistence modes. Again note that this dummy reflects the socioeconomic status of 17 individuals which belong to the Mbuti group. ${ }^{13,14}$ Appendix Table 3 also reveals that

${ }^{13}$ For completeness, we note that there are two groups, the Herero and the Nam, both of Namibia, for whom hunting and gathering are listed as important sources secondary to animal husbandry rather than to farming. These exceptions to the rule that hunting and gathering appear as supplements to agriculture, in our data, account for about a thousand observations. Moreover, in Appendix Table 4, we show alternate versions of our main regressions in which the shares of hunting, gathering, and fishing are entered as separate variables. In these specifications fishing and hunting each obtain positive and significant coefficients, whereas gathering alternates sign and is insignificant. The positive role of ancestral dependence on fishing is in line with the findings of Dalgaard et al. (2015).

${ }^{14}$ Scholars who embrace social evolutionary schema such as those of Boserup, Service, and Johnson and Earl (see above) might also wonder whether our data are supportive of the proposition that past practice of forms of agriculture that permit higher population density and longer-term food storage and that require more intensive work effort, are associated with better modern outcomes than are more "horticultural" practices. The Ethnographic Atlas data distinguish whether the main crops grown were tubers, cereals, or tree crops. Entering dummy variables for each main crop in our benchmark regressions, the respective estimated coefficients are not significant. However, an interesting observation that lends some support to the evolutionists' expectations is that when only those agricultural groups whose main crops were cereals and tree crops are included, the agriculture share coefficient remains highly significant, whereas when parallel versions of the benchmark regression are estimated using only 
lumping together societies practising intensive and extensive agriculture is justified since there does not seem to be a differential legacy of each mode.

In the rest of the columns in Table 2, we replace the country fixed effect with a fixed effect for the country-ethnic homeland in which the individual currently resides. To the extent that ancestral lifeways predict current outcomes only because lifeways predict the current state of development of different ethnic regions in a country, these fixed effects will capture such a channel. However, in practice, the coefficient on agriculture in the regressions for education and wealth is reduced by a third or less. This finding highlights that the importance of differences in ancestral lifeways in shaping individual economic outcomes is not confined to the homeland of origin of the specific group but is portable across different locations within the country.

In the third and seventh columns, we control for urban residence. Not surprisingly, this is strongly predictive of both education and wealth levels. The coefficient on agriculture falls by $31 \%$ in the case of education and $46 \%$ in the case of wealth, but remains significant in both cases. The fact that the coefficient declines suggests that one channel by which agricultural heritage improves modern outcomes is by raising the probability of having moved to a city. However, agricultural heritage evidently has an impact on current outcomes through other channels as well.

Finally, in the fourth and eighth columns, we control for a set of occupation fixed effects. ${ }^{15}$ This accounts for the possibility that the primary channel via which ancestral lifeway affects current outcomes is through an individual's choice of occupation. This allows us to rule out the possibility that our estimates simply reflect descendents of farmers still being farmers and descendents of pastoralists still being herders. Surprisingly, although the occupation dummies significantly improve the $\mathrm{R}^{2}$ of our education and wealth regressions, they only slightly change the coefficient on agriculture, implying that within broadly defined occupations today, pre-colonial dependence on agriculture influences positively individual outcomes.

\subsubsection{Including Enumeration Area Fixed Effects}

The regressions presented above include location fixed effects at the level of the Murdock map region within a country in which an individual currently lives. The justification for this approach is that these tribal regions may have characteristics that directly influence modern outcomes -indeed, these may be the same characteristics that determine traditional lifeways. We now go

observations for groups whose main crop was tubers (albeit in a much reduced sample), the coefficient on agriculture is positive but statistically insignificant (results available upon request).

${ }^{15}$ Occupational categories are: not working, professional/technical/managerial, clerical, sales, agriculture self employed, agriculture employee, household \& domestic, services, skilled manual, unskilled manual, and other. In addition, there is a category for agriculture/breeding/fishing/forest that is found in two countries (Guinea and Mali). We create a separate dummy variable for this combination category in these two countries. 
further in controlling for location-specific traits. In particular, we use the location information in the DHS, creating a dummy for every set of coordinates. This leads to a very large number of geographic fixed effects: 8,236. Correspondingly, the units within which we are exploiting variation have just a handful of households: on average around 35 respondents. The DHS sampling clusters are sufficiently small that there is no doubt that these fixed effects represent a perfect control for the economic environment that individuals face such as labor market opportunities, ethnic diversity, as well as geographic influences.

Table 3 reports the results. Compared to our regression with country-ethnic homeland fixed effects (shown in columns 1 and 4 of the table), the coefficient on agriculture falls by about one-third in the education regression and by two-thirds in the wealth regression. However, the coefficient remains statistically significant in both cases. There is some danger that the inclusion of location fixed effects represents over-controlling. The most important reason is that there is a good deal of endogeneity in the exact location of the respondents, particularly in cities where there are several sampling clusters. This sorting seems particularly salient in the case of wealth. Adding these detailed location fixed effects raises the $\mathrm{R}^{2}$ of the wealth regression from .488 to .676 , while in the case of education the rise in the $\mathrm{R}^{2}$ is from .418 to .506 . Despite this potential concern, in the rest of the paper we take these regressions with enumeration-area fixed effects as our benchmark, although in some cases we also look at the regression with country-ethnic homeland constants.

The magnitude of the key coefficients can be interpreted as follows. As mentioned above, for ethnic groups for which agriculture is the primary form of subsistence according to the Murdock Atlas, the mean of our agriculture variable is 6.3 (recall that this is on a scale of 0-9). For groups that have pastoralism as their primary source of subsistence, the mean for the agriculture variable is 2.3. Thus moving between these two groups, agriculture rises by 4 points. The coefficient in column two, 0.073 , thus implies that shifting from pastoralism to agriculture as the primary form of subsistence would raise education by 0.28 points. Since education is in turn measured on a scale where each point corresponds to roughly 3 years, this would be 0.8 years of education. The wealth coefficient in column $5,0.039$, implies that a shift from agriculture to pastoralism as the primary form of subsistence (of one's ancestors) raises the wealth index by 0.16 points. Since the wealth index corresponds to quintiles, this would be roughly equivalent to raising an individual's rank by three percentiles.

One question raised by these results is whether the coefficient on agriculture in our regressions simply reflects the numerical dominance of agriculturally descended people in modern societies. Specifically, we might expect that based on their numbers, such groups would be politically dominant, and that there there would be discrimination against groups whose ancestors were not agriculturalists. Below we show that this political discrimination story may indeed partly explain some of the observed association. However, two auxiliary pieces of evidence suggest that political discrimination is not the only mechanism at work.

The first piece of evidence comes from looking at how individuals tracing their ancestry to 
predominantly pastoral groups fare in countries where they are the absolute majority. In our sample it is only Ethiopia where this is the case. The pre-colonially pastoral groups Tigre, Afar, Arusi, Hamar, Nuer, Shebelle, Suri and Reshiat today constitute $52 \%$ of the sampled DHS individuals in Ethiopia. Despite pastoralists being in the majority, however, the coefficient on agriculture in our basic regression remains positive and significant (see Appendix Table 5).

As an alternative way to see that our evidence is not only driven by comparing descendants of pastoralists to descendants of agriculturalists we may focus on countries where none of the sampled individuals belongs to a pre-colonially predominantly pastoral group. In fact this is true for 14 countries. Appendix Table 6 Panel A replicates the specifications of Table 3 over these 14 countries. Even when there are no descendants of pastoralists present in a given country, the coefficient on agricultural dependence remains positive, significant, and indeed larger than in our baseline specification.

Even in this case, one might conceivably worry that among non-pastoral groups, those more dependent on agriculture pre-colonially may still be over-represented in the modern population, thus hold political power, which may help explain the superior economic economic performance of their members. To address this concern, we look at a subset of countries in which not only there are no descendants of pastoralists, but also among the descendants of agriculturalists, it is those whose ancestors were less dependent on agriculture who are the majority today. For example, in Benin, $70 \%$ of the sampled individuals belong to either the Fon, the Futajalonke, or the Songhai. These ethnicities derived roughly $50 \%$ of their subsistence from farming according to Murdock (1967). The other 3 sampled groups, which are the minority, namely the Gurma, the Yoruba and the Somba derived on average $70 \%$ of their livelihood from agriculture. This pattern is true for six countries in our sample. ${ }^{16}$ In Appendix table 6 Panel B, we show that our benchmark pattern established in Table 3 remains intact for these six countries. The results suggest that irrespective of their current representation in the population, members of groups that pre-colonially practised more agriculture are more wealthy and more educated. ${ }^{17}$

\footnotetext{
${ }^{16}$ The six countries in this latter group are Benin, Burkina Faso, Togo, Malawi, Guinea and Central African Republic. The other eight countries in which none of the sampled individuals were descendants of pastoralists are Cote D'Ivoire, Democratic Republic of Congo, Ghana, Mozambique, Nigeria, Senegal, Sierra Leone, and Zambia.

17 The estimates in Table 3 are purely cross sectional. In an attempt to explore whether the legacy of agricultural ancestry has been evolving over time, we estimated versions of the education and wealth regressions similar to the ones reported in this table, separately for each five-year birth cohort groups between 1935 and 1996. Appendix Figures 1a and 1b plot the estimates. The coefficients remain positive and statistically significant except for when the dependent variable is the level of wealth among the very oldest birth cohorts, which have very few members. Moreover, there is no clear evidence of a trend in the coefficients by age, as would be consistent, for example, with convergence over time between groups with different ancestral lifeways. However, the standard errors are large enough that we cannot be sure that such a trend is not present.
} 


\subsection{Heterogeneity by Occupation, Urban Status, and Country}

To assess the sensitivity of our results as well as provide some evidence on the possible channels via which ancestral lifeways affect current outcomes, we split the sample along various dimensions.

We start by splitting the sample by occupation into two broad categories: farming-related and non-farming related. ${ }^{18}$ This allows us to assess the extent to which the effect of ancestral lifeways operate in the traditional or in the modern sectors of the economy. The results are presented in Table 4. For education, agriculture remains significantly positive in both sub-samples. The coefficient on agriculture in the non-farming group (0.0727) is larger than the coefficient in the farming-related group (0.0515). This implies that agricultural ancestry has more import outside of agriculture than within it. In the case of wealth, the coefficient on agriculture also remains significant when the sample is split, with the coefficient being higher in the farming related group, although the difference is very small.

Splitting the sample into urban versus rural residence, we find an interesting difference in the results for education compared to wealth. For education, the coefficients in the two sub-samples are very similar to each other and to the corresponding coefficient in Table 3 . In the wealth regression the coefficients are again significant in the sub-samples, but in this case, the coefficient on agriculture for individuals living in rural areas is three times as large as that in urban areas. (Some part of the difference is explained by the fact that the variance of wealth in rural areas is $30 \%$ larger than in urban while the variances of the agriculture measure are almost equal in the two areas.)

Finally, we re-run our benchmark regressions separately for each country in our sample. These results are shown in Appendix Table 5 (panels $A$ and $B$ ). Depending on the specification, the coefficient on agriculture is positive and significant at the $10 \%$ level in between 10 and 14 countries. It is only negative and significant in one country. This suggests that the benchmark pattern is not driven by a handful of countries but reflects a more generalized phenomenon of the African landscape. Agricultural descent is a reliable positive predictor of contemporary individual well-being.

\subsection{Selection into Migration}

As discussed above, we are able to identify the portable component of ancestral influence on current outcomes only because we have in our sample a substantial number of people who live outside of their ancestral homelands. Using our criterion of calling someone a "mover" if they live more than 10 kilometers outside of the homeland associated with their ethnic group, this comes to 54 percent of our sample. A natural worry with our inference strategy is that people

\footnotetext{
${ }^{18}$ Farming-related includes: agriculture self employed, agriculture employee and animal breeding, fishing, and forestry. Non-farming related include all the rest (except for not working).
} 
who live outside their ancestral homelands are not randomly selected, and in particular, that the manner in which selection operates may differ according to the ancestral lifeway associated with his/her group.

As a first step in assessing whether selection into migration biases our results, we look at the extent to which ancestral lifeway itself predicts migration. We use two different measures of migration: first, the "mover" definition used above, and second, a variable from the DHS that indicates whether an individual has moved during his/her life (this latter measure is only available for a subset of respondents). The results are shown in Table 5. The first two columns show that within enumeration areas, individuals from ethnicities that historically depended more on agriculture are less likely to be classified as "movers". A person descending from a mostly agricultural group is roughly 19 percentage points less likely to be a mover than someone from a group that relied mostly on pastoralism, and this result is robust to the inclusion of occupation fixed effects. The probable explanation is that areas in which agriculture was practiced were more likely to develop cities, which in turn attracted migrants, although another possibility is that the locations of the ethnic homelands of pastoral people are not as precisely measured as that of agriculturalists, mechanically producing the observed correlations. In columns 3 and 4 of Table 5 the dependent variable is our other migration measure. Having an agricultural background is positively but insignificantly associated with the probability having moved in one's own life. ${ }^{19}$ Similarly, the correlation between having moved in life and wealth and education levels is 0.18 and 0.12 , respectively.

The finding that there is strong predictive power of ancestral lifeway for being a "mover" suggests that there could also be differential selection into migration across lifeway groups. To assess the potential effect of this selection, we repeat our benchmark regression, where besides including a "mover" dummy we also interact it with our two ancestral lifeway categories: agriculture and hunting/fishing/gathering. A finding that there is a differential impact of being a mover for people with different ancestral lifeways has two possible interpretations. One is that there is indeed differential selection into migration -- that is, that migrants from, say, homelands with agricultural lifeways differ more from those who remain behind than do migrants from homelands with pastoral lifeways. The alternative interpretation is that there is differential portability of lifeway-specific skills outside of one's own homeland (and in particular in cities, where we expect a good fraction of movers to be located). This second channel would still be consistent with the idea that ancestral lifeway is an important determinant of modern outcomes, although via a slightly different channel than the one that we have stressed above.

The results shown in Table 6 suggest that bias from differential selection into migration is not driving our main results. When education or wealth is used as the dependent variable, the interaction of agriculture (the variable of greatest interest to us) and the "mover" dummy is

${ }^{19}$ In Appendix Table 7 we show that flexibly controlling for how long the respondent has been in his current residence (information which is available for roughly half the sample) in the benchmark specification does not alter the results. This suggests that differences in the length of integration in the current communities is unlikely to be driving the observed pattern. 
insignificant, while the coefficient on agriculture itself remains significant. This suggests that movers from agricultural areas are not systematically different than movers from historically pastoral areas.

The last split of the sample we attempted is motivated by the destination of the "movers." Naturally, for those of agricultural ancestry, currently residing in some other ethnic homeland which also used to be mostly agricultural in the pre-colonial times may not entail a significant loss in the ethnic-specific knowledge set compared to a "mover" of pastoral background. What would be more surprising is to find that descendants of agricultural groups perform better than those of pastoral descent even within enumeration areas in ethnic homelands that used to be mostly pastoral historically, where if anything those of pastoral background would have a natural advantage. Appendix Table 8 presents the results. Overall, respondents of groups that historically derived a larger share of subsistence from pastoralism are performing worse in both historically agricultural and historically pastoral regions, suggesting that differential portability of ethnic-specific skills across different ecological areas is unlikely to be the main driver of the uncovered relationship.

\section{Origins of Lifeways}

So far we have focused our attention on the question of how ancestral lifeways are related to individual outcomes today. A natural question is how ancestral lifeways themselves are determined. This is potentially important for several reasons. Most significantly, one might worry that the same factors that determine lifeways also determine individual outcomes. For example, certain cultures might be more inclined to undertake long-term investments that would be required in farming, and so members of these groups would be more likely to farm and to be economically successful, but farming itself would not be relevant. A second reason for studying the determinants of lifeways is to put more flesh on the social evolutionary narrative presented above.

The most natural determinant of whether a group has historically practiced agriculture is the quality of the land itself. It would not be surprising if agriculture were more common in areas where it was more feasible. Figure 1a portrays the degree of pre-colonial dependence on agriculture (from the Murdock Atlas) and Figure 1b maps the underlying suitability of land for agriculture across tribal regions (constructed by Ramankutty et al., 2001). Table 7 shows regressions of ancestral subsistence on agriculture, pastoralism, and hunt/gather/fish, respectively, on land quality. As expected, the coefficient on land quality is significantly positive in the regression for agriculture and significantly negative in the regression for pastoralism. It is insignificant in the regression for gather/hunt/fish.

\subsection{Instrumental Variables Regressions}

Tables 8 presents instrumental variables regressions with education and wealth as dependent variables, using land suitability to instrument for the share of agriculture. In addition to dealing 
with the possible endogeneity of agriculture mentioned above, the IV procedure also corrects for measurement error in agriculture as a share of traditional subsistence, which is presumably non-negligible. ${ }^{20}$ Columns 1 and 4 include country-ethnic-homeland fixed effects whereas the rest of the columns include enumeration area constants. It is useful to keep in mind that looking within the latter absorbs a significant fraction of variation of both the instrument and the instrumented variable. Across all specifications the coefficient on agriculture is positive and statistically significant and the IV coefficients are moderately smaller compared to the respective OLS shown on Table 3.

The uncovered evidence supports a story in which ethnic groups which found themselves on land that was suitable for agriculture were more likely to take this up as a means of subsistence, and that engaging in agriculture then conferred portable characteristics on individuals from these ethnic groups that made them more prone to succeed after they migrated away from their homelands.

\section{$6 \quad$ Ethnic and Linguistic Families}

A threat to our identification of a channel whereby participating in agriculture endows ethnic groups with characteristics that lead to success in the modern economy would be if pre-existing ethnic characteristics drove both the likelihood that a group took up agriculture and economic outcomes in the modern world. An example would be if some groups were naturally more acquisitive, and were able to push less acquisitive groups onto marginal land. ${ }^{21}$ Unfortunately, we do not have direct measures of these potential characteristics (although some of these are likely to be reflected in the other pre-colonial traits recorded in the Ethnographic Atlas, whose variation, as we show below, does not seem to explain away our findings). As a partial fix for this concern, we repeat our benchmark regressions including fixed effects for linguistic families and subfamilies as well as ethnic clusters. Groups in the same family will, we presume, have broadly comparable cultural origins, and thus it seems more likely that variation in agriculture as a source of livelihood within an ethnic/linguistic category will be more likely due to variation in

\footnotetext{
${ }^{20}$ The peculiar geography of Africa in terms of its suitability for the Tsetse fly also circumscribed the use of animals in specific parts of the continent and shaped the locations where pastoralism was a viable mode of production, see Alsan (2015).

21 There is a large literature in linguistics and anthropology arguing that the spread zones of agriculturalists and pastoralists and their languages following the Neolithic Revolution trace closely land endowments that were amenable to agricultural and herding activities, respectively. Hence, pastoralism is viewed as an adaptation to ecological niches unable to support much agricultural production (Richerson et al.; Bellwood (2001)). This observation might raise the possibility that pastoralists attain lower outcomes today due to some genetic inferiority that consigned their ancestors to marginal environments centuries or even millennia ago. We think it unlikely that any differences predating ancestral sorting into lifeways has strong effects on capabilities today given than both cultural and genetic forces have been at work for many intervening centuries. For example, even if it had been the case that pastoralists are descended from lineages that lost the struggle for good agricultural land due to lack of physical strength or toughness, casual empiricism casts doubt on the proposition that the pastoralists of recent times are lacking in those respects--consider the repeated historical conquests of agrarian by pastoralist armies.
} 
opportunity to practice agriculture than to variation in broad cultural characteristics.

We consider 3 different levels of linguistic and ethnic aggregation. In particular, the 187 groups in our dataset correspond to 6 language phylums as defined in the Murdock Atlas entry (v98), 13 linguistic subfamilies (entry v99 in Murdock Atlas) and 36 ethnic clusters which correspond to Murdock's (1959) heading of the respective chapters. It is important to keep in mind that for the construction of ethnic clusters Murdock relied on agricultural features, among other things (Murdock p.42-43 "common cultigens"). This implies that the latter classification absorbs most of the variation in our explanatory variable imposing a rather stringent test for our thesis.

To give some examples of the various groupings, in Kenya, the Kikuyu, Meru, and Kamba are all part of the Kenya Highland Bantu ethnic family, the Niger-Congo language phylum, and the Niger Congo: Bantoid or Central language sub-family, while the Luo and Kipsigi are part of the Nilotes ethnic family, the Chari-Nile language family and the Eastern Nilotic or Sudanic language sub-family. However, ethnic and linguistic categories do not always line up so neatly. For example, the Kissi, Kpelle and Bete in Guinea are all in the ethnic cluster Kru and Peripheral Mande, but this ethnic cluster spans 3 linguistic subfamilies, namely: Niger-Congo: Atlantic or West Atlantic (Kissi), Niger-Congo: Kwa (Bete), and Niger-Congo: Mande (Kpelle). Similarly, ethnicities in different ethnic clusters may be linguistically related. In Burkina Faso, the Bisa, Bobo, Gurma, Lobi, and Senufo all belong to the Niger-Congo Gur or Voltaic language sub-family, but the first of these groups belongs to the Central Bantu ethnic cluster while the other four groups belong to the Voltaic ethnic cluster.

As one would expect, these groupings by themselves explain a good deal of the variation in agriculture as a source of livelihood. The $\mathrm{R}^{2}$ from regressing agricultural dependence on the set of linguistic sub-family dummies is .37 , and from regressing it on the set of ethnic dummies the R-squared is .67.

Tables 9 shows the effect of including these dummies in our benchmark regressions. Adding the six linguistic family dummies has no effect on either the size or significance of the coefficient on agriculture in either the education or the wealth regressions. By contrast, when we use the 13 linguistic sub-family dummies, the coefficient on agriculture in the education regression falls by a little less than half and remains significant at the $5 \%$ level, while in the case of the wealth regression, the coefficient does not change much and remains highly significant. Surprisingly, when we use 36 dummies for the respective ethnic clusters, there is, once again, very little change in the coefficients on agriculture in either the education or wealth regressions, and they remain highly significant. Hence, even within ethnic families, whose constituent groups are presumably broadly comparable along several dimensions, tracing one's ancestry to an ethnicity that practised more agriculture historically translates robustly into better economic outcomes today. Overall, the evidence suggests that unobserved heterogeneity across large groupings is unlikely to be driving the bulk of our results. 


\section{Possible Channels: Why is An Agricultural Past Advantageous?}

We finally turn to investigating the possible channels through which ancestral lifeway affects present individual outcomes. Our exploration starts by looking at other pre-colonial traits and continues by investigating possible influences on agricultural ethnic groups that might have taken place during the colonial era. We also explore whether the observed pattern is driven by the unequal treatment of descendants of pastoral groups by the central government, finding some support. Finally, using alternative survey data we find differences in attitudes and demeanor between descendants of pastoralists and agriculturalists that help account for differences in wealth and educational outcomes.

\subsection{Pre-Colonial Characteristics}

The Murdock Atlas provides a wealth of information on ethnic-specific traits besides their means of subsistence. In this section, we experiment by adding a number of these to the right hand side of our benchmark regressions for education and wealth. While this is in part an attempt to identify the channels of causation from ancestral lifeways to modern outcomes, it can also be seen as an additional test of the robustness of the findings above. We would expect that a society's means of feeding itself would determine a great many other societal characteristics. ${ }^{22}$ Alternatively, it might be that ethnic groups that take up agriculture already had certain characteristics. In either of these cases, it may be these characteristics that affect outcomes of individuals once they leave their traditional occupations and homelands. Finding that accounting for such a characteristic significantly reduced the coefficient on agriculture would be evidence for this story.

The pre-colonial characteristics that we examine are the following: polygyny is a dichotomous indicator for the practice of men marrying multiple wives; clans is a dichotomous variable assigned a value of 1 if community marriage organization is coded as characterized by clan communities or clan barrios and not segmented communities, exogamous communities, or segmented communities without local exogamy; settlements refers to position on a spectrum ranging from 1 for fully migratory and nomadic to 8 for complex settlements, with permanence and density of settlement increasing with the value assigned; local jurisdiction indicates the degree of jurisdictional hierarchy (existence of governance structures) at the local level (e.g., village); political centralization indicates jurisdictionary hierarchy above the level of the local community, coded 1 (no supra-community hierarchy) to 5 (four levels of hierarchy above the local community); class stratification is a dichotomous indicator equal to 0 if no class stratification exists "among freemen," and 1 if the Atlas records class stratification, wealth distinctions, elite class, dual classes, or "complex" class structure; elections takes value 1 if succession to the office of local headman was by election or other formal consensus, otherwise zero; slavery refers to presence of an internal institution of slave ownership (as opposed to the

22 The notion that culture is a "superstructure" determined by a society's "mode of production" or material base, was famously proposed by Karl Marx and championed in the field of anthropology by Marvin Harris (1997), among others. 
external slave trade, which is considered in the subsequent exercise) ${ }^{23}$; and property, set to 0 if "inheritance rule for real property (land)" is coded "absence of individual property rights," and to 1 if response code is "matrilineal," "patrilineal" or "other heirs." We refer to these characteristics as "pre-colonial," since we believe that they are measuring aspects of a tribal society that pre-date European interference. In addition to assessing how these characteristics affect the coefficient on agriculture, it is also of interest to look at their own effects.

The results are shown in Table 10 (Panels A and B). Each column shows results from two regressions that use the same sample. The top line shows the coefficient on the agriculture share in a regression in which the only right hand side variables are the agriculture and hunt/gather/fish shares as well as our "simple controls" and coordinate fixed effects. The bottom part of the table shows coefficients from a regression that adds to these one or more of the pre-colonial control variables. We follow this procedure because missing observations in the Atlas differ across pre-colonial variables which means that the sample varies significantly across specifications (and, as seen in the last column, is greatly reduced when we use all of the pre-colonial characteristics together).

The first finding in this table is that controlling for pre-colonial characteristics, either one at a time or all together, has little effect on the coefficient on agriculture when looking at the effect on education in Panel A. The coefficient always remains statistically significant, and does not change in magnitude much when characteristics are entered one at a time. Even when all of the pre-colonial characteristics are entered in the regression together, the drop in the coefficient is negligible (from 0.089 to 0.085 ), and it remains significant at the $1 \%$ level.

In the regressions with wealth as the dependent variable in Panel $\mathrm{B}$, it is once again the case that entering pre-colonial characteristics one at a time has little bearing on the magnitude of the coefficient on agriculture, which is always highly significant. However, when all of the pre-colonial characteristics are entered jointly, the coefficient on agriculture becomes statistically insignificant. In this specification, none of the pre-colonial characteristic variables is individually significant. Similarly, when these pre-colonial characteristics are added one at a time into the education and wealth regressions, none of them obtains significant coefficients in both of them. ${ }^{24}$ We take these findings as an indication that within villages among movers there is not one pre-colonial trait with stronger influence than ancestral dependence on agriculture in explaining present individual-level variation in economic performance.

\footnotetext{
${ }^{23}$ It is not clear the degree to which the practise of indigenous slavery in the pre-colonial period was shaped by the incidence of slave raids in the context of the European slave trades.

${ }^{24}$ Michalopoulos and Papaioannou (2013) show that regional development is higher in ethnic homelands of politically complex societies in the pre-colonial era. We complement their finding by uncovering that individuals tracing their ancestry to politically centralized/stratified groups and residing outside their ancestral homelands also enjoy higher levels of wealth (although they are no more educated).
} 


\subsection{Colonial Roots}

In Table 11, we account for variables reflecting factors from the colonial and early postcolonial period that might influence economic outcomes of descendants today. We include two measures intended to capture the impact of the slave trade: slaves taken per square kilometer of the ancestral ethnic homeland and distance from the centroid of the ancestral homeland to the sea. We also include two variables that are intended to measure other influences of Europeans: missions per square kilometer of the ancestral ethnic homeland, and distance of the homeland's centroid to the capital city. Finally, we include measures of religion at the individual level. The reference group in this case is Christian, with the two other categories being Muslim and other/no religion. ${ }^{25}$

Unlike the pre-colonial measures, inclusion of the new variables in Table 11 has relatively little effect on the size of our sample, and in no case does their inclusion alter the significance of the coefficient on agriculture. Including all of them together, the coefficient on agriculture in the education regression falls by one fifth, and that in the wealth regression hardly changes. Of the additional variables, the most notable effects are from religion. Non-Christians have lower levels of educational attainment, while for wealth, being other/no religion has a negative effect, but this is not the case for Muslims. There are also indications that presence of Christian missions (established during the colonial era in the ancestral group's homeland) improves descendants' current outcomes. In contrast, contact with Europeans engendered by proximity to the capital city shows a negative effect, if any. We find little sign of an effect of the slave trade in these specifications. We return to the impact of missions in section 7.4.

\subsection{Cultural Roots: Attitudes Towards Violence, Perceptions of Survey Enumerators}

A natural theory explaining persistent effect of ancestral lifeways on modern outcomes is that there is cultural transmission of traits related to lifeways that impact behavior today. The range of potentially relevant traits is enormous, and measurement of any particular cultural trait is difficult. For example, Galor and Ozak (forthcoming) establish a positive link between geographic endowments conducive to agriculture and patience as measured in contemporary populations.

Why the different lifeways of farming and herding may give rise to differences in traits such as patience, attitudes towards violence, and differences in views of gender relations, is a question that lies beyond the scope of our data and analysis. Some have suggested that pastoralists cultivate attitudes of greater vigilance and readiness to resort to use of force because their main source of livelihood and store of wealth is easily movable. Physically closer, longer term settlement may favor more cooperative cultures among agricultural groups. The fact that women

${ }^{25}$ The DHS religion variable (v130) is coded differently for each country. For some countries, we collapsed several groups to form the "Christian" category. All the countries provided enough information for us to put individuals into one of our three categories, except for Namibia, which does not have a unique category for "Muslim". But considering that Namibia is overwhelmingly Christian (only 25 observations are non-Christian), this should not be a big problem. 
perform most agricultural labor might combine with the lesser importance of the male advantage in warfare and defense to give women less status disadvantage in agricultural societies, although women's traditional status in rural Africa is frequently judged to be low. Moving further from the differences we have been able to document, agriculturalists may develop greater tolerance for repetitive effort than do pastoralists due to the different demands of their ways of wresting a living from nature. A "work ethic" more ready for urban modernity might therefore mark agriculturalists on average, which could further contribute to greater success in schooling and in wealth-generating activities.

Data availability leads us to focus our exploratory exercises on two features sometimes attributed to pastoralist cultures and seeming at first blush to have the potential to reduce the success of individuals in modernizing societies. They are: a reputed proclivity to violence, in men (Nisbett and Cohen, 1996; Pinker, 2011; Grosjean, (2014), and alleged low status of women (Bodley, 2011; Krätli, 2001) ${ }^{26}$ The first trait might disadvantage men as candidates for occupations requiring cooperative interaction with those from other cultures, and the second might, among other things, cause greater gender disparities, lower investment in education and health of women, and lead to lower female participation in the labor force. Unfortunately, our data do not permit us either to disentangle the two factors or to determine exactly how--i.e., in one of the manners just mentioned, or in some other way or ways--they influence outcomes.

In the DHS there is a set of attitudinal measures that reflect some combination of men's attitudes towards both violence and women. Specifically, five questions in the DHS ask respondents about the circumstances under which it would be acceptable for a man to beat his wife. ${ }^{27}$ As our dependent variable, we use the first principal component of these five measures, which on average explains $59.9 \%$ of the variation in each of them. The standard deviation of the dependent variable is 1.73 . This measure reflects a mix of attitudes toward women and proclivity toward violence.

Table 12 shows the results. We include our standard set of controls, and also experiment with including a control for being Muslim, since Muslims are somewhat overrepresented among pastoralists and reduced freedom or lower status for women is sometimes attributed to Muslim cultures. Being from an ethnicity that was traditionally dependent on agriculture has a negative and significant effect on the reported acceptability of violence towards women when the Muslim control is not included, and is significant at the $10 \%$ level when the control is included.

${ }^{26}$ In a laboratory experiment involving university student subjects in five culturally and institutionally distinct countries on three continents, Ahn et al. (2015) find subjects in Mongolia substantially less successful than those in Austria, the U.S., Mexico and South Korea, at foregoing theft from fellow group members to foster socially efficient production. Unlike the other countries, the ancestors of the Mongolian students were overwhelmingly practitioners of pastoralism a few generations ago. However, it lies beyond the scope of our investigation to draw conclusions regarding the claims concerning either proclivity to violence or low status of women; among the sources referenced, both Bodley and Krätli view the claim of low status of women as being oversimplified.

27 The variables are MV744A-MV744E. The circumstances are: wife goes out without telling him; wife neglects the children; wife argues with him; wife refuses to have sex with him; wife burns the food. 
We also checked whether the likelihood of sending a girl to school relative to that of sending a boy differed in households according to the DHS data depending on the degree of ancestral reliance of agriculture of the household head. We found no significant difference here. This suggests that variation in the acceptability of violence toward women discussed above may be more informative about differences in attitudes towards violence than about differences in attitudes towards women, but strong conclusions are probably unwarranted in the absence of further evidence.

In addition to this result from our DHS data, we also find evidence suggestive of difference in interpersonal interaction style from a set of questions that enumerators of the Afrobarometer 4 survey are asked to complete following each interview. The enumerator codes (a) whether the respondent seemed hostile, (b) whether the respondent appeared bored, (c) whether the respondent was uncooperative, (d) whether the respondent appeared impatient, (e) whether the respondent seemed suspicious, and (f) whether the respondent struck the enumerator as dishonest in his or her responses. The Afrobarometer survey includes information on the ethnicity of each respondent, so we are able to link the coded data of more than 25,500 surveyed individuals in 19 countries to ancestral ethnicity and thus to the same Ethnographic Atlas lifeway shares used in the rest of our analysis. See the summary statistics in Appendix Table 9.

Columns two through seven of Table 13 show the results of OLS regressions of the enumerator codings for respondent characteristics (a) - (f) on our agriculture and hunting/fishing/gathering share variables plus age, age squared, a female dummy, location fixed effects, a mover dummy, and 724 enumerator fixed effects, with errors clustered at the ethnic identity of each respondent. The estimated coefficients indicate that relative to the omitted ancestral lifeway of animal husbandry, greater ancestral reliance on agriculture significantly reduces impressions of boredom, impatience and dishonesty, and reduces with marginal (in)significance impressions that the respondent is uncooperative and suspicious. Thus the same enumerator finds descendants of pastoralists decidedly less easy to interact with than descendants of agriculturalists. This suggests a difference in disposition to which the ancestral lifeway may originally have contributed, and that may potentially affect the economic success of these descendents even in quite different modern environments. But we cannot rule out that nearly all enumerators are descendants of non-pastoralists and that their judgments are influenced by cultural presuppositions and not objectively warranted.

To get a sense of how much of the effect of lifeway on education and wealth might be explained by the differences documented in Table 13, we estimate regressions paralleling our benchmark regressions (Table 3) using observations from the Afrobarometer Round 4 Surveys rather than the DHS. The first column of Table 14 presents this baseline specification which reassuringly confirms our finding about the significant positive impact of ancestral reliance on agriculture on education (there is not a wealth variable in the Afrobarometer comparable to the DHS measure). Exploiting variation within the 3,748 enumeration areas in the Afrobarometer 4, effectively 
comparing the education outcomes across roughly 6 respondents per village, those of agricultural ancestry are more educated. In columns 2 - 5 we introduce interviewer-specific constants whereas in column 3 we add controls for the enumerators' judgments of the surveyed individuals. We find that adding the enumerator scores on the respondent's personality characteristics modestly reduces the coefficient on agriculture by a little under $12 \%$, from 0.018 to 0.0159 which suggests that a moderate share of the influence of agricultural ancestry may operate through the channel of such personality traits. ${ }^{28}$

\subsection{Institutional Roots: Treatment by Europeans and Political Influence}

Although the findings in section 7.3 suggest that culture, personality traits and/or attitudes that members of pastoralist groups have handed down over the generations, may negatively affect their economic outcomes today, we cannot rule out that the treatment that they and their ancestors received at the hands of colonizers and post-colonial political elites also play a part in explaining their outcomes. For example, if European administrators, settlers and missionaries treated pastoralists less favorably than agriculturalists, whether out of prejudice that the former were more "culturally backward" or less like themselves, or due simply to logistical constraints on interaction with diffuse and mobile populations, and if postcolonial African elites also dealt less favorably with pastoralists, then it might be the inferior treatment by others, rather than internalized disadvantageous traits, that explain today's less favorable outcomes.

A first hint of such differential treatment builds on the finding in Table 11 that past presence of Christian missions has been economically advantageous to groups in whose midst they were situated. If there were fewer missions in pastoralist homelands, this could have proven disadvantageous, perhaps because members of pastoralist groups would have had less exposure to "modernizing" influences, including suggestions of the value of literacy. The correlations between the extent of reliance on animal husbandry by an Atlas ethnic group and number of missions in the homeland, the number of missions per square kilometer of homeland area, and a dummy variable for presence of any mission in the homeland, are all negative and significant. Since there were fewer missions among pastoralists and past mission presence predicts better contemporary outcomes, we see one possible pathway for pastoralism to have disadvantaged groups' descendants via an influence on treatment by Europeans. While statistically significant, however, the economically insubstantial change in the estimated coefficient on agriculture when the control for missions is added in Table 11 implies that this specific factor is not quantitatively important in its own right.

We also find evidence that those of pastoralist descent have, or at least perceive themselves to have, less political influence than those of agricultural background, in contemporary Africa. The literature on African political economy provides abundant evidence of the role played by ethnic

${ }^{28}$ Compared to the DHS education estimates the difference in the coefficient magnitude is driven by the fact that in the Afrobarometer Surveys the education variable is more detailed and takes 10 distinct values corresponding to different educational levels. We take the log to reduce the skewness in the distribution. 
favoritism in determining access to employment and government services; see, for example, Franck and Rainer (2012) and Kudamatsu (2009). Hence, a natural candidate for explaining the observed differences in the socioeconomic status between pastoral and agricultural groups is their difference in political power. We attempted to shed light on this issue performing the following three tests.

First, in an attempt to gauge the political representation of a group we followed Michalopoulos and Papaioannou (forthcoming) and linked the groups in the Ethnic Power Relationship dataset (EPR) to the Murdock Atlas groups. The former dataset created by Wimmer, Cederman, and Min (2009) records periods/years of ethnic-based discrimination. Using this direct measure as the outcome of interest (more precisely using a dummy indicating whether a group has even been discriminated between 1960-2010) we find that groups more dependent on pastoralism pre-colonially have experienced during the postcolonial era a $4 \%$ increase in the likelihood of discrimination (with a sample mean of $16 \%$ ). This association albeit marginally insignificant $(p<$ .15 ) is suggestive of the disadvantage that descendants of pastoral groups face in the political sphere (table is available upon request).

Second, motivated by the finding of Francois, Rainer and Trebbi (2014) that across roughly 15 democratic African countries ruling coalitions are surprisingly large and that political power is allocated proportionally to population shares across ethnic groups, we added as a control in the benchmark regressions the log of the number of individuals belonging to the respondent's ethnic group within country (we also tried the share of the group in the country's sampled population, finding similar results). This variable is meant to capture the de facto influence of that group in the political arena. We find that adding the population size (share) of the ethnic group in the main Table 3 does not affect the quantitative significance of our estimates.

Third, data from the Afrobarometer indicate that those whose ancestors relied more on animal husbandry than agriculture perceive their ethnic group to be less politically influential. This is shown in column (1) of Table 13 where the dependent variable is the respondent's' perception of his group's political influence. Because the dependent variable's coding assigns a smaller value for greater perceived influence, the negative significant coefficient on agriculture means that the more did the respondent's ancestral group relied on agriculture, the greater the perceived political influence of her group.

Although it is possible that the reported self-perception of less influence on the parts of respondents having pastoralist ethnic backgrounds simply reflect some personality trait that perhaps correlates with impatience, suspicion, and other characteristics judged present by the enumerators, it is also possible that the groups in question are in fact less influential (on average) in their nations' political scenes, and that this is indeed one of the pathways explaining the inferior economic outcomes of current members of those groups. With respect to magnitudes, comparison of regressions (2) and (4) of Table 14 indicate that controlling for differences in perceived political influence lowers the magnitude of the coefficient on agriculture by $8 \%$, suggesting that the factor has non-negligible importance, but is relatively less important than the personality traits that the same table's exercises suggest can account for about $12 \%$ of 
the estimated coefficient on agriculture. In column 5 of Table 14 accounting for both differences in perceived personality traits as well as perceived political influence of the group reduces the coefficient on ancestral dependence on agriculture by $19 \%$, leaving it marginally significant at the $10 \%$ level.

\section{Conclusion}

On the eve of the "Scramble for Africa" the continent was replete with examples of almost every kind of pre-industrial subsistence economy, from hunter-gatherers, to nomadic pastoralists, to shifting and intensive agriculturalists. Today, five generations later, the descendants of these groups are often intermingled within urban settings. Does one's lineage in terms of pre-colonial lifeways matter for today's individual outcomes?

In this paper, we have looked at agriculture and pastoralism not as current occupations but as ancestral ones, investigating whether the pre-colonial lifeways of contemporary Africans' ethnic groups predict the current economic outcomes of their members. In survey data from 21 sub-Saharan countries, we find that the greater was one's ancestral group's reliance on agriculture, the better one's outcomes are today, even when controlling for a large number of potentially relevant factors and when focusing on those living at some remove from the ancestral homeland, those in cities, and those engaged in non-agriculture and non-animal raising occupations. We confirmed our main result also in a second substantial data set, reproduced it using land suitability to instrument for reliance on agriculture, determined that it is not attributable to the shared heritages of linguistic or ethnic family groupings, and identified possible channels through which an ancestry reliant on animal husbandry contributes to inferior contemporary outcomes. Among the traits in question, we found provisional evidence relating to violence and impatience, but dimensions of culture for which we presently lack measures, such as attitudes towards work, might be as or more important. Possibly economic lifeway in past centuries selected for cultural and attitudinal traits that served useful functions under the conditions then extant but that, transmitted to more recent generations in the course of their upbringing and socialization, confer a handicap on those of one background relative to those of the other.

These findings leave open the question of whether what accounts for the outcomes observed is in fact the portable traits which those of pastoral ethnicity have carried with them into agrarian and urban environments, traits that in and of themselves disadvantage their bearers, or whether instead the prejudices and unfavorable treatment of them by, first, European missionaries and colonial officials and, subsequently, African elites and even their neighbors of non-pastoralist ancestry, are to blame. We find some evidence consistent with a prejudicial or at least differential treatment pathway in the facts that presence of missions is found to be economically helpful and that missions were significantly less common among pastoralists. Additional evidence comes from pastoralist descendants' self-reported perception that their groups have less influence than others in their countries' politics today. Although we controlled for enumerator effects, the survey enumerators' reports of impatience and uncooperativeness on 
the parts of respondents of pastoralist background might still partly reflect prejudices against pastoralists, if the vast majority of enumerators have agriculturalist roots.

While we are unable to fully separate the "inherent trait" from the "treatment by others" type explanations, it seems likely that at least part of the disadvantage exhibited by those of non-agricultural ancestry does reflect deep cultural factors, and that our results therefore stand as evidence of the persistent impact of history on current economic outcomes. Our findings bear comparison with cross-country evidence that earlier and more extended agrarian state development confers economic advantages today at the national level, but they may constitute the first of this kind that document the influence of historical way of life at the individual level. It suggests an arrow of causality running from environmental factors through economic adaptation and thence to culture and persistent traits, with those traits exerting an influence for some generations past removal of the culture-bearers from the originating environment. It joins in this respect a growing literature on culture and the economy, a literature whose relevance to future policy-making begins with offering a better understanding of the factors that lie behind the challenges facing economically disadvantaged groups. 


\section{References}

Abramitzky Ran, Leah Boustan and Katherine Eriksson, 2014, "A Nation of Immigrants: Assimilation and Economic Outcomes in the Age of Mass Migration," Journal of Political Economy, 122 (3), 467-717.

Ahn, T.K., Loukas Balafoutas, Mongoljin Batsaikhan, Francisco Campos-Ortiz, Louis Putterman and Matthias Sutter, 2015, "Security of Property as a Public Good: Institutions, Socio-Political Environment and Experimental Behavior in Five Countries," Brown University Working Paper 2012-18, revised.

Alesina, Alberto, Paola Giuliano and Nathan Nunn, 2013, "On the Origins of Gender Roles: Women and the Plough," Quarterly Journal of Economics 128 (2): 469-530.

Alesina, Alberto, Stelios Michalopoulos Stelios, Elias Papaioannou, 2016, "Ethnic Inequality" Journal of Political Economy, 124 (2): 428-488.

Alsan, Marcella. 2015. "The Effect of the TseTse Fly on African Development." American Economic Review, 105(1): 382-410.

Bellwood, Peter, "Early Agriculturalist Population Diasporas? Farming, Languages, and Genes," Annual Review of Anthropology, 2001, 30, 181-207.

Bockstette Valerie, Areendam Chanda, Louis Putterman, 2002, "States and Markets: The Advantage of an Early Start”, Journal of Economic Growth, 7(4): 347-369.

Bodley, John, 2011, Cultural Anthropology: Tribes, States, and the Global System. Lanham, MD: AltaMira Press.

Borcan Oana, Ola Olsson, and Louis Putterman, 2014, "State History and Economic Development: Evidence from Six Millennia”, Brown University Working Paper.

Carneiro, Robert L., 2003, Evolutionism in Cultural Anthropology: A Critical History. Boulder, CO: Westview Press.

Carroll, C., Rhee, B. and Rhee, C. 1994. Are there cultural effects on saving? Some cross-sectional evidence. Quarterly Journal of Economics 109, 685-99.

Clark Gregory, 2015 "The Son Also Rises: Surnames and the History of Social Mobility," Princeton University Press

Dalgaard, Carl-Johan, Beck Knudsen, Anne Sofie, Pablo Selaya, 2015, "The Bounty of the Sea 
and Long-Run Development", mimeo University of Copenhagen.

Diamond, Jared, 1997, Guns, Germs and Steel: The Fates of Human Societies. New York: W.W.Norton.

Diamond, Jared and Peter Bellwood, 2003, "Farmers and Their Languages: The First Expansions," Science 300, 597 - 603.

Easterly, William, and Ross Levine, 2012, "The European Origins of Economic Development," No. w18162. NBER.

Easterly, William, and Ross Levine, 1997, "Africa's Growth Tragedy: Policies and Ethnic Divisions," Quarterly Journal of Economics, 112 (4): 1203-1250.

Fenske, James, 2013, "Does Land Abundance Explain African Institutions?" The Economic Journal, 123 (573), 1363-1390.

Fernandez, Raquel, "Does Culture Matter?" in J. Benhabib, M. O. Jackson and A. Bisin, editors, Handbook of Social Economics, Vol. 1A, North-Holland, 2011

Fernandez, Raquel, and Alessandra Fogli, "Culture: An Empirical Investigation of Beliefs, Work, and Fertility," American Economic Journal: Macroeconomics 1(1), 146-177, 2009.

Franck Raphael, and Ilia Rainer, 2012, “Does the leader's ethnicity matter? Ethnic favoritism, education and health in sub-Saharan Africa, American Political Science Review, 106(2), 294-325.

Francois, Patrick, Ilia Rainer, and Francesco Trebbi, 2015, "How is Power Shared in Africa?", Econometrica, 83 (2), 465-503.

Galor, Oded, and Omer Ozak, 2016, “The Agricultural Origins of Time Preference,” American Economic Review, forthcoming.

Giuliano, Paola, and Nathan Nunn, 2013, "The Transmission of Democracy: From the Village to the Nation-State," American Economic Review: Papers \& Proceedings 103 (3): 86 - 92.

Grosjean, Pauline, 2014, "A History of Violence: The Culture of Honor and Homicide in the U.S. South," Journal of the European Economic Association, 12 (5), 1285-1316.

Guell, Maia, Jose Rodriguez Mora, and Chris Telmer, "The Informational Content of Surnames, the Evolution of Intergenerational Mobility and Assortative Mating," Review of Economic Studies 82 (2): 693-735. 
Harris, Marvin, 1997, "Culture, People, Nature: An Introduction to General Anthropology" (7th Edition). Pearson.

Johnson, Allen and Timothy Earle, eds., 2000, "The Evolution of Human Societies: From Foraging Group to Agrarian State," 2nd edition. Stanford: Stanford University Press.

Krätli, Saverio, 2001, "Educating Nomadic Herders Out of Poverty? Culture, Education and Pastoral Livelihood in Turkana and Karamoja." Sussex, UK: Institute of Development Studies, University of Sussex.

Kudamatsu Masayuki, 2009, “Ethnic Favoritism: Micro Evidence from Guinea”, working paper IIES.

Michalopoulos, Stelios, Alireza Naghavi and Giovanni Prarolo, 2012, "Trade and Geography in the Origins and Spread of Islam," NBER Working Paper No. 18438.

Michalopoulos, Stelios, 2012, "The Origins of Ethnolinguistic Diversity," American Economic Review, 2012, 102(4): 1508-1539.

Michalopoulos, Stelios and Elias Papaioannou, 2013, "Pre-colonial Ethnic Institutions and Contemporary African Development," Econometrica, 81(1): 113-152.

Michalopoulos, Stelios and Elias Papaioannou, 2014, "National Institutions and Subnational Development in Africa," Quarterly Journal of Economics 129 (1): 151-213.

Michalopoulos, Stelios and Elias Papaioannou, 2015, "The Long-Run Effects of the Scramble for Africa," American Economic Review, forthcoming.

Murdock, George P. 1959. Africa: its peoples and their culture history. New York: McGraw-Hill.

Murdock, George Peter, 1967, "Ethnographic Atlas: A Summary." Pittsburgh, PA: University of Pittsburgh Press.

Nisbett, Richard and Dov Cohen, 1996, "Culture of Honor: The Psychology of Violence in the South." Boulder, CO: Westview Press.

Nunn N, 2014, "Historical Development". Aghion P, Durlauf S Handbook of Economic Growth. Vol. 2. North-Holland, pp. 347-402.

Nunn, Nathan, and Leonard Wantchekon, 2011, "The Slave Trade and the Origins of Mistrust in Africa." American Economic Review, 101(7): 3221-52.

Oliver, Roland and J.D. Fage, A Short History of Africa, 6th Edition. Harmondsworth: Penguin. 
Osafo-Kwaako, Philip, and James A Robinson, 2013, "Political Centralization in Pre-Colonial Africa." Journal of Comparative Economics 41 (1): 534-564

Pinker, Steven, 2011. “The Better Angels of our Nature.” New York: Viking.

Putterman, Louis, 2008, "Agriculture, Diffusion and Development: Ripple Effects of the Neolithic Revolution" Economica, 75 (300): 729-748.

Putterman, Louis, David Weil, 2010, "Post-1500 Population Flows and The Long-Run Determinants of Economic Growth and Inequality", The Quarterly Journal of Economics 125 (4): 1627-1682.

Ramankutty, Navin, Jonathan A. Foley, John Norman, and Kevin McSweeney, 2002 "The Global Distribution of Cultivable Lands: Current Patterns and Sensitivity to Possible Climate Change." Global Ecology and Biogeography 11 (5): 377-92.

Richerson, Peter J., Monique Mulder and Bryan Vila, 2001, "Principles of Human Ecology. University of California - Davis," http://www.des.ucdavis.edu/faculty/Richerson/BooksOnline/101 text.htm.

Rutstein, Shea O. and Kiersten Johnson, 2004, "The DHS Wealth Index. DHS Comparative Reports No. 6." Calverton, Maryland: ORC Macro.

http://dhsprogram.com/pubs/pdf/CR6/CR6.pdf

Sahlins, Marshall, 1972, "Stone Age Economics." Chicago: Aldine-Atherton.

Sahlins, Marshall, and Elman R. Service, eds., 1960, "Evolution and Culture." Ann Arbor: University of Michigan Press.

Service, Elman R., 1971. "Cultural Evolutionism: Theory and Practice." NY: Holt, Rinehart and Winston.

Spolaore, Enrico, and Romain Wacziarg, "How Deep are the Roots of Economic Development?" Journal of Economic Literature 2013, 51(2), 325-369.

Wimmer, Cederman, and Min "Ethnic politics and armed conflict. A configurational analysis of a new global dataset." American Sociological Review, 74(2), 2009. 
Figures 1a, 1b:

Pre-Colonial Dependence on Agriculture and Land Suitability for Agriculture Across Ethnic Groups
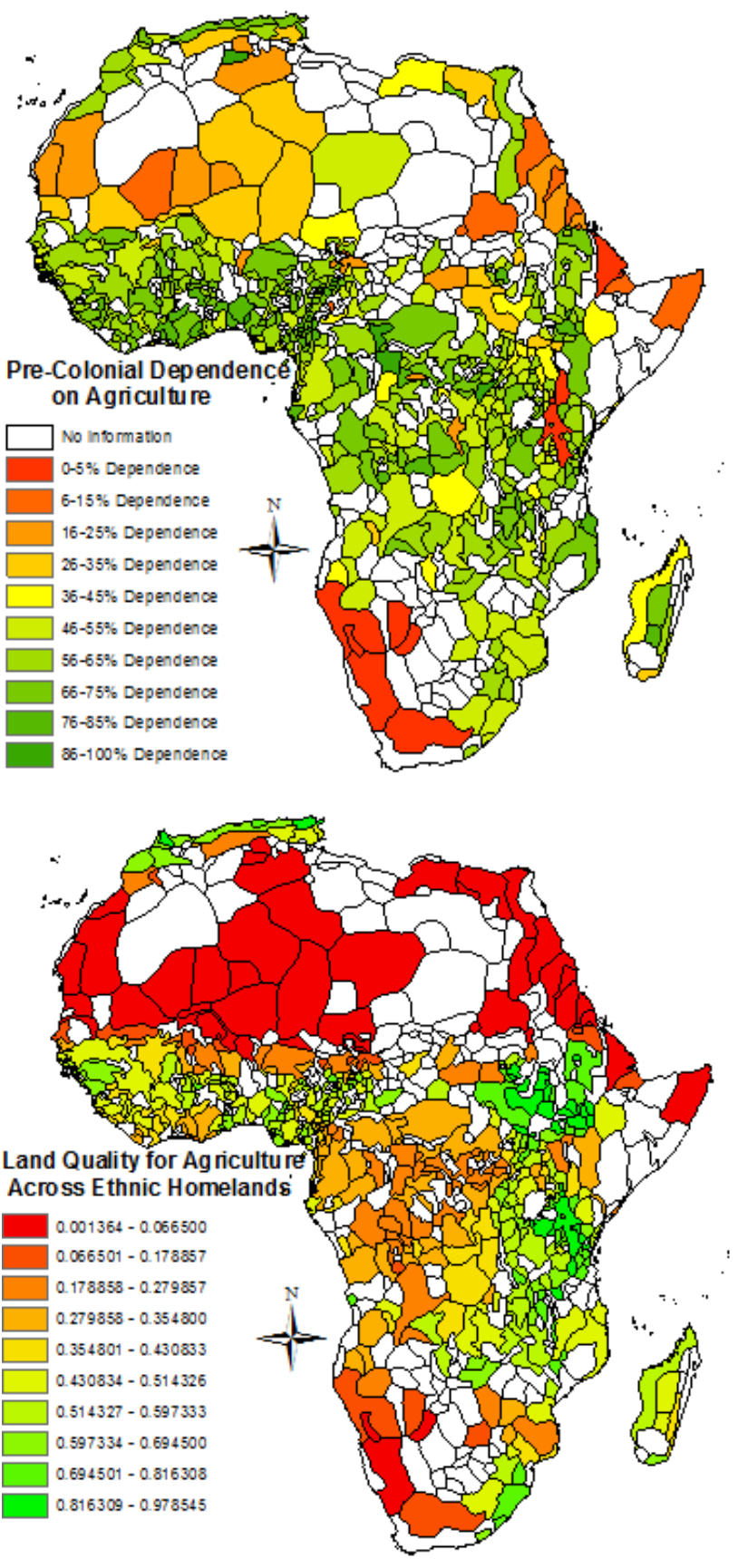
Table 1: Explanatory Power of Various Fixed Effects Models

\begin{tabular}{|c|cccc|}
\hline $\mathrm{R}^{2}$ from FE Regressions & $\begin{array}{c}\text { All } \\
\text { Education }\end{array}$ & $\begin{array}{c}\text { All } \\
\text { Wealth }\end{array}$ & $\begin{array}{c}\text { Movers } \\
\text { Education }\end{array}$ & $\begin{array}{c}\text { Movers } \\
\text { Wealth }\end{array}$ \\
\hline Country FE & 0.159 & 0.013 & 0.147 & 0.035 \\
\hline Homeland FE & 0.293 & 0.233 & 0.292 & 0.298 \\
\hline Ethnicity FE & 0.265 & 0.142 & 0.258 & 0.188 \\
\hline Country-Ethnicity FE & 0.282 & 0.164 & 0.283 & 0.215 \\
\hline Country-Homeland FE & 0.303 & 0.249 & 0.306 & 0.320 \\
\hline $\begin{array}{c}\text { Country-Homeland FE \& } \\
\text { Country-Ethnicity FE }\end{array}$ & 0.325 & 0.283 & 0.338 & 0.362 \\
\hline Observations & 285,218 & 269,992 & 154725 & 146,158 \\
\hline
\end{tabular}

Ethnicity: ethnic identity of the respondent as matched to Murdock's (1967) classification

Ethnic Homeland: current ethnic location of each respondent based on Murdock's 1959 location of groups

Table 2. Benchmark - DHS Regressions within Ethnic Homelands

\begin{tabular}{|c|c|c|c|c|c|c|c|c|}
\hline VARIABLES & $\begin{array}{c}1 \\
\text { Education }\end{array}$ & $\begin{array}{c}2 \\
\text { Education }\end{array}$ & $\begin{array}{c}3 \\
\text { Education }\end{array}$ & $\begin{array}{c}4 \\
\text { Education }\end{array}$ & $\begin{array}{c}5 \\
\text { Wealth }\end{array}$ & $\begin{array}{c}6 \\
\text { Wealth }\end{array}$ & $\begin{array}{c}7 \\
\text { Wealth }\end{array}$ & $\begin{array}{c}8 \\
\text { Wealth }\end{array}$ \\
\hline agriculture & $\begin{array}{c}0.2337 * * * \\
(0.0432)\end{array}$ & $\begin{array}{c}0.1498 * * * \\
(0.0259)\end{array}$ & $\begin{array}{c}0.1034 * * * \\
(0.0212)\end{array}$ & $\begin{array}{c}0.1011 * * * \\
(0.0191)\end{array}$ & $\begin{array}{c}0.2271 * * * \\
(0.0459)\end{array}$ & $\begin{array}{c}0.1808 * * * \\
(0.0338)\end{array}$ & $\begin{array}{c}0.0980^{* * * *} \\
(0.0230)\end{array}$ & $\begin{array}{c}0.0984 * * * \\
(0.0228)\end{array}$ \\
\hline gather/hunt/fish & $\begin{array}{c}0.2095 * * * \\
(0.0547)\end{array}$ & $\begin{array}{c}0.1026 * * * \\
(0.0214)\end{array}$ & $\begin{array}{c}0.0918 * * * \\
(0.0200)\end{array}$ & $\begin{array}{c}0.0911 * * * \\
(0.0185)\end{array}$ & $\begin{array}{c}0.1585^{* * * *} \\
(0.0495)\end{array}$ & $\begin{array}{c}0.0655 * * * \\
(0.0250)\end{array}$ & $\begin{array}{c}0.0470 * * * \\
(0.0159)\end{array}$ & $\begin{array}{c}0.0512 * * * \\
(0.0156)\end{array}$ \\
\hline urban & & & $\begin{array}{c}0.9199 * * * \\
(0.0357)\end{array}$ & $\begin{array}{c}0.7079 * * * \\
(0.0292)\end{array}$ & & & $\begin{array}{c}1.6290 * * * \\
(0.0474)\end{array}$ & $\begin{array}{c}1.4284 * * * \\
(0.0486)\end{array}$ \\
\hline Simple Controls & Yes & Yes & Yes & Yes & Yes & Yes & Yes & Yes \\
\hline Country FE & Yes & No & No & No & Yes & No & No & No \\
\hline $\begin{array}{l}\text { Country-Ethnic } \\
\text { Homeland FE }\end{array}$ & No & Yes & Yes & Yes & No & Yes & Yes & Yes \\
\hline Occupation FE & No & No & No & Yes & No & No & No & Yes \\
\hline Observations & 285,155 & 285,155 & 285,155 & 285,155 & 269,929 & 269,929 & 269,929 & 269,929 \\
\hline $\mathrm{R}^{2}$ & 0.239 & 0.350 & 0.418 & 0.493 & 0.056 & 0.266 & 0.488 & 0.515 \\
\hline
\end{tabular}

Standard errors in parentheses are clustered at the ethnicity level; simple controls include age, age squared, a female dummy, and a mover dummy; *** $\mathrm{p}<0.01, * * \mathrm{p}<0.05, * \mathrm{p}<0.1$ 
Table 3 - Panel A. Benchmark: DHS Regressions within Villages/Towns

\begin{tabular}{lcccccc}
\hline VARIABLES & 1 & 2 & 3 & 4 & 5 & 6 \\
agriculture & Education & Education & Education & Wealth & Wealth & Wealth \\
\hline & $0.1034^{* * *}$ & $0.0731^{* * *}$ & $0.0694^{* * *}$ & $0.0980^{* * * *}$ & $0.0394^{* * * *}$ & $0.0384^{* * *}$ \\
gather/hunt/fish & $(0.0212)$ & $(0.0147)$ & $(0.0128)$ & $(0.0230)$ & $(0.0073)$ & $(0.0071)$ \\
& $0.0918^{* * *}$ & $0.0708^{* * *}$ & $0.0681^{* * *}$ & $0.0470^{* * *}$ & $0.0179^{* *}$ & $0.0193^{* * *}$ \\
urban & $(0.0200)$ & $(0.0155)$ & $(0.0140)$ & $(0.0159)$ & $(0.0073)$ & $(0.0070)$ \\
& $0.9199^{* * *}$ & & & $1.6290^{* * *}$ & & \\
Simple Controls & $(0.0357)$ & & & $(0.0474)$ & & \\
Country-Ethnic & Yes & Yes & Yes & Yes & Yes & Yes \\
Homeland FE & Yes & No & No & Yes & No & No \\
Coordinates FE & No & Yes & Yes & No & Yes & Yes \\
Occupation FE & No & No & Yes & No & No & Yes \\
Observations & 285,155 & 285,155 & 285,155 & 269,929 & 269,929 & 269,929 \\
$\mathrm{R}^{2}$ & 0.418 & 0.506 & 0.559 & 0.488 & 0.676 & 0.681 \\
\hline
\end{tabular}

Standard errors in parentheses are clustered at the ethnicity level; simple controls include age, age squared, a female dummy, and a mover dummy.

$* * * \mathrm{p}<0.01, * * \mathrm{p}<0.05, * \mathrm{p}<0.1$ 
Table 4: Heterogeneity by Occupation and Location

\begin{tabular}{|c|c|c|c|c|c|c|c|c|}
\hline VARIABLES & $\begin{array}{c}1 \\
\text { Education } \\
\text { Farming- } \\
\text { Related } \\
\end{array}$ & $\begin{array}{c}2 \\
\text { Education } \\
\text { Non-Farming } \\
\text { Related } \\
\end{array}$ & $\begin{array}{c}3 \\
\text { Education } \\
\text { Urban }\end{array}$ & $\begin{array}{c}4 \\
\text { Education } \\
\text { Rural }\end{array}$ & $\begin{array}{c}5 \\
\text { Wealth } \\
\text { Farming- } \\
\text { Related } \\
\end{array}$ & $\begin{array}{c}6 \\
\text { Wealth } \\
\text { Non-Farming } \\
\text { Related } \\
\end{array}$ & $\begin{array}{c}7 \\
\text { Wealth } \\
\text { Urban }\end{array}$ & $\begin{array}{c}8 \\
\text { Wealth } \\
\text { Rural }\end{array}$ \\
\hline agriculture & $\begin{array}{c}0.0515^{* * * *} \\
(0.0106)\end{array}$ & $\begin{array}{c}0.0727 * * * \\
(0.0233)\end{array}$ & $\begin{array}{c}0.0764 * * * \\
(0.0196)\end{array}$ & $\begin{array}{c}0.0703 * * * \\
(0.0114)\end{array}$ & $\begin{array}{c}0.0431 * * * \\
(0.0098)\end{array}$ & $\begin{array}{c}0.0390 * * * \\
(0.0077)\end{array}$ & $\begin{array}{c}0.0206^{* * *} \\
(0.0055)\end{array}$ & $\begin{array}{c}0.0645^{* * *} \\
(0.0109)\end{array}$ \\
\hline gather/hunt/fish & $\begin{array}{c}0.0416^{* * *} \\
(0.0113)\end{array}$ & $\begin{array}{c}0.0791 * * * \\
(0.0224)\end{array}$ & $\begin{array}{c}0.0849 * * * \\
(0.0208)\end{array}$ & $\begin{array}{c}0.0550^{* * * *} \\
(0.0116)\end{array}$ & $\begin{array}{l}0.0219 * * \\
(0.0101)\end{array}$ & $\begin{array}{c}0.0222 * * * \\
(0.0074)\end{array}$ & $\begin{array}{c}0.0095 \\
(0.0066)\end{array}$ & $\begin{array}{c}0.0278^{* * *} \\
(0.0096)\end{array}$ \\
\hline $\begin{array}{l}\text { Simple Controls } \\
\text { Coordinates FE }\end{array}$ & $\begin{array}{l}\text { Yes } \\
\text { Yes }\end{array}$ & $\begin{array}{l}\text { Yes } \\
\text { Yes }\end{array}$ & $\begin{array}{l}\text { Yes } \\
\text { Yes }\end{array}$ & $\begin{array}{l}\text { Yes } \\
\text { Yes }\end{array}$ & $\begin{array}{l}\text { Yes } \\
\text { Yes }\end{array}$ & $\begin{array}{l}\text { Yes } \\
\text { Yes }\end{array}$ & $\begin{array}{l}\text { Yes } \\
\text { Yes }\end{array}$ & $\begin{array}{l}\text { Yes } \\
\text { Yes }\end{array}$ \\
\hline $\begin{array}{l}\text { Observations } \\
\mathrm{R}^{2}\end{array}$ & $\begin{array}{c}97,599 \\
0.460\end{array}$ & $\begin{array}{c}101,565 \\
0.463\end{array}$ & $\begin{array}{c}97,702 \\
0.370\end{array}$ & $\begin{array}{c}187,453 \\
0.486\end{array}$ & $\begin{array}{c}92,156 \\
0.443\end{array}$ & $\begin{array}{c}94,685 \\
0.693\end{array}$ & $\begin{array}{c}92,726 \\
0.600\end{array}$ & $\begin{array}{c}177,203 \\
0.460\end{array}$ \\
\hline
\end{tabular}

Standard errors in parentheses, clustered at the ethnicity level. Simple controls include age, age squared, a female dummy, and a mover dummy; Farming-related industries include self-employed agriculture, agricultural employee, forest, breeding, hunting and fishing. Nonfarming related industries include professional, technical, managerial positions, clerical positions, sales, household and domestic, services, skilled manual, and unskilled manual. Not working individuals are excluded.

$* * * \mathrm{p}<0.01, * * \mathrm{p}<0.05, * \mathrm{p}<0.1$ 
Table 5. Determinants of Migration

\begin{tabular}{lcccc}
\hline VARIABLES & $\begin{array}{c}1 \\
\text { Mover }\end{array}$ & Mover & $\begin{array}{c}3 \\
\text { Moved in life }\end{array}$ & $\begin{array}{c}4 \\
\text { Moved in life }\end{array}$ \\
\hline agriculture & $-0.0465^{* *}$ & $-0.0464^{* *}$ & 0.0052 & 0.0049 \\
& $(0.0212)$ & $(0.0211)$ & $(0.0052)$ & $(0.0050)$ \\
gather/hunt/fish & $-0.1179^{* * *}$ & $-0.1177^{* * *}$ & -0.0062 & -0.0061 \\
& $(0.0254)$ & $(0.0253)$ & $(0.0053)$ & $(0.0051)$ \\
Simple Controls & Yes & Yes & Yes & Yes \\
Coorrdinates FE & Yes & Yes & Yes & Yes \\
Occupation FE & No & Yes & No & Yes \\
Observations & 285,163 & 285,163 & 188,268 & 188,268 \\
$\mathrm{R}^{2}$ & 0.768 & 0.768 & 0.229 & 0.233 \\
\hline
\end{tabular}

Standard errors in parentheses are clustered at the ethnicity level; Simple controls include age, age squared, a female dummy, and a mover dummy in columns $3 \& 4$;

$* * * \mathrm{p}<0.01, * * \mathrm{p}<0.05, * \mathrm{p}<0.1$

Table 6. Effect of Differential Selection into Migration

\begin{tabular}{lcccc}
\hline & $(1)$ & $(2)$ & $(3)$ & $(4)$ \\
VARIABLES & Education & Education & Wealth & Wealth \\
\hline \multirow{2}{*}{ agriculture } & & & & \\
& $0.2808^{* * *}$ & $0.2711^{* * *}$ & $0.2408^{* * *}$ & $0.2351^{* * *}$ \\
gather/hunt/fish & $(0.0607)$ & $(0.0543)$ & $(0.0570)$ & $(0.0494)$ \\
& $0.2817^{* * *}$ & $0.2748^{* * *}$ & $0.1723^{* * *}$ & $0.1793^{* * *}$ \\
mover & $(0.0683)$ & $(0.0638)$ & $(0.0586)$ & $(0.0500)$ \\
& $0.7465^{* *}$ & $0.7812^{* *}$ & 0.4978 & $0.5583^{*}$ \\
mover X agric & $(0.3505)$ & $(0.3282)$ & $(0.3454)$ & $(0.3087)$ \\
& -0.0571 & -0.0731 & -0.0184 & -0.0400 \\
mover X ghf & $(0.0515)$ & $(0.0482)$ & $(0.0445)$ & $(0.0398)$ \\
& $-0.1087^{* *}$ & $-0.1156^{* * *}$ & -0.0202 & -0.0370 \\
Simple Controls & $(0.0482)$ & $(0.0442)$ & $(0.0553)$ & $(0.0473)$ \\
Occupation FE & Yes & Yes & Yes & Yes \\
Country FE & No & Yes & No & Yes \\
Observations & 285,155 & 285,155 & 269,929 & 269,929 \\
$\mathrm{R}^{2}$ & 0.241 & 0.38 & 0.056 & 0.219 \\
\hline
\end{tabular}

Standard errors in parentheses are clustered at the ethnicity level; Simple controls include age, age squared and a female dummy. Mover is a dummy variable that equals one if an individual is at least 10 kilometers away from her ancestral homeland; *** $\mathrm{p}<0.01, * *$ $\mathrm{p}<0.05, * \mathrm{p}<0.1$ 


\begin{tabular}{lccc}
\hline & $(1)$ & $(2)$ & $(3)$ \\
VARIABLES & agriculture & pastoralism & gather/hunt/fish \\
\hline Suitablity for & $0.6525^{* * *}$ & $-0.7053^{* * *}$ & 0.0468 \\
Agriculture) & $(0.1576)$ & $(0.1726)$ & $(0.1010)$ \\
Observations & 187 & 187 & 187 \\
$\mathrm{R}^{2}$ & .137 & .149 & -0.004 \\
\hline Robust standard errors in parentheses; $* * * \mathrm{p}<0.01, * * \mathrm{p}<0.05, * \mathrm{p}<$
\end{tabular}

Table 8. IV for Full Sample

\begin{tabular}{lcccccc}
\hline & $(1)$ & $(2)$ & $(3)$ & $(4)$ & $(5)$ & $(6)$ \\
VARIABLES & Education & Education & Education & Wealth & Wealth & Wealth \\
\hline agriculture & $0.1215^{* *}$ & $0.0567^{*}$ & $0.0513^{*}$ & $0.1191^{* * *}$ & $0.0267^{* *}$ & $0.0233^{* *}$ \\
& $(0.0551)$ & $(0.0335)$ & $(0.0297)$ & $(0.0599)$ & $(0.0118)$ & $(0.0115)$ \\
gather/hunt/fish & $0.0883^{* *}$ & $0.0629^{* * *}$ & $0.0593^{* * *}$ & 0.0327 & 0.0114 & 0.0115 \\
& $(0.0349)$ & $(0.0209)$ & $(0.0185)$ & $(0.0353)$ & $(0.0079)$ & $(0.0073)$ \\
Simple Controls & Yes & Yes & Yes & Yes & Yes & Yes \\
Country-Ethnic & Yes & No & No & Yes & No & No \\
Homeland FE & No & Yes & Yes & No & Yes & Yes \\
Coordinates FE & No & No & Yes & No & No & Yes \\
Occupation FE & & & & & & \\
First Stage F- & 22.29 & 31.33 & 31.35 & 24.37 & 35.92 & 35.96 \\
Statistic & & & & & & \\
Observations & 285,139 & 285,072 & 285,072 & 269,912 & 269,845 & 269,845 \\
\hline
\end{tabular}

Standard errors in parentheses are clustered at the Atlas levels. Simple controls include age, age squared, a female dummy, and a mover dummy; $* * * p<0.01, * * p<0.05, * p<0.1$ 
Table 9. Variation from Within Linguistic and Ethnic Families

\begin{tabular}{lcccccc}
\hline & 1 & 2 & 3 & 4 & 5 & 6 \\
VARIABLES & Education & Education & Education & Wealth & Wealth & Wealth \\
\hline \multicolumn{7}{c}{ Panel A: Exploiting Within-Linguistic-Family Variation } \\
agriculture & $0.0735^{* * *}$ & $0.0768^{* * *}$ & $0.0734^{* * *}$ & $0.0393^{* * *}$ & $0.0381^{* * *}$ & $0.0373^{* * *}$ \\
& $(0.0148)$ & $(0.0164)$ & $(0.0147)$ & $(0.0074)$ & $(0.0076)$ & $(0.0074)$ \\
gather/hunt/fish & $0.0712^{* * *}$ & $0.0683^{* * *}$ & $0.0658^{* * *}$ & $0.0178^{* *}$ & $0.0182^{* *}$ & $0.0195^{* * *}$ \\
& $(0.0156)$ & $(0.0148)$ & $(0.0135)$ & $(0.0073)$ & $(0.0070)$ & $(0.0067)$ \\
Linguistic & No & Yes & Yes & No & Yes & Yes \\
Family(v98) FE & & & & & & \\
Observations & 280,557 & 280,557 & 280,557 & 265,331 & 265,331 & 265,331 \\
$\mathrm{R}^{2}$ & 0.508 & 0.509 & 0.561 & 0.671 & 0.671 & 0.677 \\
\hline
\end{tabular}

\section{Panel B: Exploiting Within-Linguistic-Sub-Family Variation}

\begin{tabular}{lcccccc} 
agriculture & $0.0731 * * *$ & $0.0414 * *$ & $0.0406^{* *}$ & $0.0398^{* * *}$ & $0.0341 * * *$ & $0.0326 * * *$ \\
& $(0.0147)$ & $(0.0203)$ & $(0.0174)$ & $(0.0077)$ & $(0.0095)$ & $(0.0087)$ \\
gather/hunt/fish & $0.0708^{* * *}$ & 0.0295 & 0.0277 & $0.0177 * *$ & $0.0239^{* * *}$ & $0.0233^{* * *}$ \\
& $(0.0155)$ & $(0.0220)$ & $(0.0193)$ & $(0.0076)$ & $(0.0077)$ & $(0.0071)$ \\
Linguistic & No & Yes & Yes & No & Yes & Yes \\
Subfamily(v99) FE & & & & & & \\
Observations & 285,155 & 271,781 & 271,781 & 256,555 & 256,555 & 256,555 \\
$\mathrm{R}^{2}$ & 0.506 & 0.511 & 0.563 & 0.669 & 0.670 & 0.675 \\
\hline
\end{tabular}

\section{Panel C: Exploiting Within-Ethnic-Cluster Variation}

\begin{tabular}{lcccccc} 
agriculture & $0.0731^{* * *}$ & $0.0711^{* * *}$ & $0.0645 * * *$ & $0.0394 * * *$ & $0.0367 * *$ & $0.0372 * *$ \\
& $(0.0147)$ & $(0.0146)$ & $(0.0125)$ & $(0.0073)$ & $(0.0154)$ & $(0.0167)$ \\
gather/hunt/fish & $0.0708^{* * *}$ & $0.0732^{* * *}$ & $0.0670^{* * *}$ & $0.0179 * *$ & $0.0257^{*}$ & $0.0281^{*}$ \\
& $(0.0155)$ & $(0.0147)$ & $(0.0131)$ & $(0.0073)$ & $(0.0145)$ & $(0.0160)$ \\
Ethnic Cluster FE & No & Yes & Yes & No & Yes & Yes \\
Observations & 285,155 & 285,155 & 285,155 & 269,929 & 269,929 & 269,929 \\
$\mathrm{R}^{2}$ & 0.506 & 0.509 & 0.561 & 0.676 & 0.676 & 0.682 \\
\hline
\end{tabular}

Standard errors in parentheses are clustered at the ethnicity level; All specifications include age, age squared, a female dummy, and a mover dummy (simple controls) as well as enumeration area fixed effects; Columns $3 \& 6$ also include a vector of occupational dummies.

$* * * \mathrm{p}<0.01, * * \mathrm{p}<0.05, * \mathrm{p}<0.1$ 
Table 10 - Panel A. Pre-Colonial Characteristics. Education

\begin{tabular}{|c|c|c|c|c|c|c|c|c|c|c|}
\hline VARIABLES & $\begin{array}{c}1 \\
\text { Education } \\
\end{array}$ & $\begin{array}{c}2 \\
\text { Education }\end{array}$ & $\begin{array}{c}3 \\
\text { Education } \\
\end{array}$ & $\begin{array}{c}4 \\
\text { Education } \\
\end{array}$ & $\begin{array}{c}5 \\
\text { Education } \\
\end{array}$ & $\begin{array}{c}6 \\
\text { Education } \\
\end{array}$ & $\begin{array}{c}7 \\
\text { Education } \\
\end{array}$ & $\begin{array}{c}8 \\
\text { Education } \\
\end{array}$ & $\begin{array}{c}9 \\
\text { Education } \\
\end{array}$ & $\begin{array}{c}10 \\
\text { Education } \\
\end{array}$ \\
\hline agriculture & $\begin{array}{c}0.0733 * * * \\
(0.0147)\end{array}$ & $\begin{array}{c}0.0870 * * * \\
(0.0165)\end{array}$ & $\begin{array}{c}0.0741 * * * \\
(0.0155)\end{array}$ & $\begin{array}{c}0.0746^{* * *} * \\
(0.0155)\end{array}$ & $\begin{array}{c}0.0746 * * * \\
(0.0155)\end{array}$ & $\begin{array}{c}0.0760 * * * \\
(0.0143)\end{array}$ & $\begin{array}{c}0.0666^{* * * *} \\
(0.0234)\end{array}$ & $\begin{array}{c}0.0748 * * * \\
(0.0135)\end{array}$ & $\begin{array}{c}0.0710 * * * \\
(0.0158)\end{array}$ & $\begin{array}{c}0.0889 * * \\
(0.0385)\end{array}$ \\
\hline agriculture & $\begin{array}{c}0.0821 * * * \\
(0.0171)\end{array}$ & $\begin{array}{c}0.0862 * * * \\
(0.0165)\end{array}$ & $\begin{array}{c}0.0782 * * * \\
(0.0146)\end{array}$ & $\begin{array}{c}0.0760 * * * \\
(0.0156)\end{array}$ & $\begin{array}{c}0.0743 * * * \\
(0.0154)\end{array}$ & $\begin{array}{c}0.0760 * * * \\
(0.0143)\end{array}$ & $\begin{array}{c}0.0622 * * * \\
(0.0226)\end{array}$ & $\begin{array}{c}0.0674 * * * \\
(0.0126)\end{array}$ & $\begin{array}{c}0.0735 * * * \\
(0.0161)\end{array}$ & $\begin{array}{c}0.0846^{* * *} \\
(0.0287)\end{array}$ \\
\hline gather/hunt/fish & $\begin{array}{c}0.0784 * * * \\
(0.0163)\end{array}$ & $\begin{array}{c}0.0607 * * * \\
(0.0160)\end{array}$ & $\begin{array}{c}0.0672 * * * \\
(0.0174)\end{array}$ & $\begin{array}{c}0.0781 * * * \\
(0.0170)\end{array}$ & $\begin{array}{c}0.0717 * * * \\
(0.0163)\end{array}$ & $\begin{array}{c}0.0651 * * * \\
(0.0161)\end{array}$ & $\begin{array}{c}0.0639 * * \\
(0.0296)\end{array}$ & $\begin{array}{c}0.0643 * * * \\
(0.0143)\end{array}$ & $\begin{array}{c}0.0607 * * * \\
(0.0157)\end{array}$ & $\begin{array}{l}0.0487^{*} \\
(0.0275)\end{array}$ \\
\hline polygyny & $\begin{array}{l}0.0537 * \\
(0.0322)\end{array}$ & & & & & & & & & $\begin{array}{c}0.1058 \\
(0.0749)\end{array}$ \\
\hline clans & & $\begin{array}{c}-0.0415 \\
(0.0445)\end{array}$ & & & & & & & & $\begin{array}{c}-0.0469 \\
(0.0621)\end{array}$ \\
\hline settlement pattern & & & $\begin{array}{c}-0.0182 * \\
(0.0108)\end{array}$ & & & & & & & $\begin{array}{c}-0.0158 \\
(0.0177)\end{array}$ \\
\hline local jurisdictional & hierarchy & & & $\begin{array}{l}0.0514 * \\
(0.0274)\end{array}$ & & & & & & $\begin{array}{c}0.1039^{* *} \\
(0.0497)\end{array}$ \\
\hline Political Centraliza & tion & & & & $\begin{array}{c}0.0109 \\
(0.0204)\end{array}$ & & & & & $\begin{array}{l}-0.0248 \\
(0.0359)\end{array}$ \\
\hline class stratification & & & & & & $\begin{array}{c}0.0120 \\
(0.0394)\end{array}$ & & & & $\begin{array}{c}0.0420 \\
(0.0656)\end{array}$ \\
\hline elections & & & & & & & $\begin{array}{l}-0.1021 \\
(0.0884)\end{array}$ & & & $\begin{array}{c}-0.1424 \\
(0.1022)\end{array}$ \\
\hline slavery & & & & & & & & $\begin{array}{c}-0.1885 * * * \\
(0.0363)\end{array}$ & & $\begin{array}{c}-0.1254 * * \\
(0.0547)\end{array}$ \\
\hline property & & & & & & & & & $\begin{array}{c}-0.1633 * * \\
(0.0699)\end{array}$ & $\begin{array}{c}-0.1913 * * \\
(0.0922)\end{array}$ \\
\hline Coordinates FE & Yes & Yes & Yes & Yes & Yes & Yes & Yes & Yes & Yes & Yes \\
\hline Observations & 281,005 & 260,798 & 268,649 & 269,443 & 269,443 & 258,246 & 217,898 & 269,953 & 256,542 & 175,604 \\
\hline $\mathrm{R}^{2}$ & .508 & .514 & .511 & .511 & .511 & .513 & .516 & .512 & .508 & .529 \\
\hline
\end{tabular}

Standard errors in parentheses, clustered at the ethnicity level. Simple controls always included. These are age, age squared, a female dummy, and a mover dummy; In each column there are two estimates of agriculture. The first estimate (above the undelined line) corresponds to a regression where we do not control for the other pre-colonial characteristic focusing on the same sample. The second estimate (below the underlined line) corresponds to the estimate of the regression when we add the pre-colonial trait under consideration. $* * * \mathrm{p}<0.01, * * \mathrm{p}<0.05,{ }^{*} \mathrm{p}<0.1$ 
Table 10 - Panel B. Pre-Colonial Characteristics. Wealth

\begin{tabular}{|c|c|c|c|c|c|c|c|c|c|c|}
\hline VARIABLES & $\begin{array}{c}1 \\
\text { Wealth } \\
\end{array}$ & $\begin{array}{c}2 \\
\text { Wealth } \\
\end{array}$ & $\begin{array}{c}3 \\
\text { Wealth } \\
\end{array}$ & $\begin{array}{c}4 \\
\text { Wealth } \\
\end{array}$ & $\begin{array}{c}5 \\
\text { Wealth } \\
\end{array}$ & $\begin{array}{c}6 \\
\text { Wealth } \\
\end{array}$ & $\begin{array}{c}7 \\
\text { Wealth } \\
\end{array}$ & $\begin{array}{c}8 \\
\text { Wealth } \\
\end{array}$ & $\begin{array}{c}9 \\
\text { Wealth } \\
\end{array}$ & $\begin{array}{c}10 \\
\text { Wealth } \\
\end{array}$ \\
\hline agriculture & $\begin{array}{c}0.0395 * * * \\
(0.0074)\end{array}$ & $\begin{array}{c}0.0410 * * * \\
(0.0077)\end{array}$ & $\begin{array}{c}0.0407 * * * \\
(0.0078)\end{array}$ & $\begin{array}{c}0.0408 * * * \\
(0.0078)\end{array}$ & $\begin{array}{c}0.0408 * * * \\
(0.0078)\end{array}$ & $\begin{array}{c}0.0422 * * * \\
(0.0075)\end{array}$ & $\begin{array}{c}0.0218 * * * \\
(0.0083)\end{array}$ & $\begin{array}{c}0.0386 * * * \\
(0.0074)\end{array}$ & $\begin{array}{c}0.0340 * * * \\
(0.0073)\end{array}$ & $\begin{array}{c}0.0214 * * \\
(0.0086)\end{array}$ \\
\hline gather/hunt/fish & $0.0177 * *$ & $0.0151^{*}$ & $0.0157 * *$ & $0.0158 * *$ & $0.0186^{* *}$ & $0.0216 * * *$ & 0.0028 & $0.0195^{* *}$ & $0.0147 *$ & -0.0187 \\
\hline polygyny & $\begin{array}{c}(0.0086) \\
-0.0026 \\
(0.0178)\end{array}$ & $(0.0085)$ & $(0.0076)$ & $(0.0077)$ & $(0.0076)$ & $(0.0078)$ & $(0.0119)$ & $(0.0077)$ & $(0.0082)$ & $\begin{array}{c}(0.0173) \\
-0.0547 \\
(0.0424)\end{array}$ \\
\hline clans & & $\begin{array}{l}-0.0217 \\
(0.0264)\end{array}$ & & & & & & & & $\begin{array}{c}-0.0460 \\
(0.0443)\end{array}$ \\
\hline settlement pattern & & & $\begin{array}{c}-0.0052 \\
(0.0051)\end{array}$ & & & & & & & $\begin{array}{c}0.0029 \\
(0.0077)\end{array}$ \\
\hline local jurisdictional & hierarchy & & & $\begin{array}{c}-0.0085 \\
(0.0127)\end{array}$ & & & & & & $\begin{array}{c}0.0110 \\
(0.0251)\end{array}$ \\
\hline elections & & & & & & & $\begin{array}{c}0.0278 \\
(0.0310)\end{array}$ & & & $\begin{array}{c}-0.0402 \\
(0.0482)\end{array}$ \\
\hline slavery & & & & & & & & $\begin{array}{c}-0.0202 \\
(0.0211)\end{array}$ & & $\begin{array}{c}0.0154 \\
(0.0313)\end{array}$ \\
\hline property & & & & & & & & & $\begin{array}{c}-0.0267 \\
(0.0381)\end{array}$ & $\begin{array}{c}-0.0315 \\
(0.0713)\end{array}$ \\
\hline Coordinates FE & Yes & Yes & Yes & Yes & Yes & Yes & Yes & Yes & Yes & Yes \\
\hline Observations & 265,779 & 245,572 & 253,423 & 254,217 & 254,217 & 244,512 & 207,903 & 254,727 & 243,557 & 167,621 \\
\hline $\mathrm{R}^{2}$ & .672 & .675 & .678 & .677 & .677 & .669 & .675 & .669 & .672 & .678 \\
\hline
\end{tabular}

Standard errors in parentheses, clustered at the Atlas level. Simple controls included are: age, age squared, a female dummy, and a mover dummy; In each column there are two estimates of agriculture. The first estimate (above the undelined line) corresponds to a regression where we do not control for the other pre-colonial characteristic focusing on the same sample. The second estimate (below the underlined line) corresponds to the estimate of the regression when we add the pre-colonial trait under consideration. ${ }^{* * *} \mathrm{p}<0.01,{ }^{* *} \mathrm{p}<0.05,{ }^{*} \mathrm{p}<0.1$ 
Table 11. Colonial Roots

\begin{tabular}{|c|c|c|c|c|c|c|c|c|c|c|}
\hline VARIABLES & $\begin{array}{c}(1) \\
\text { Education }\end{array}$ & $\begin{array}{c}(2) \\
\text { Education } \\
\end{array}$ & $\begin{array}{c}(3) \\
\text { Education }\end{array}$ & $\begin{array}{c}(4) \\
\text { Education } \\
\end{array}$ & $\begin{array}{c}(5) \\
\text { Education } \\
\end{array}$ & $\begin{array}{c}(6) \\
\text { Wealth }\end{array}$ & $\begin{array}{c}(7) \\
\text { Wealth }\end{array}$ & $\begin{array}{c}(8) \\
\text { Wealth }\end{array}$ & $\begin{array}{c}(9) \\
\text { Wealth } \\
\end{array}$ & $\begin{array}{c}(10) \\
\text { Wealth }\end{array}$ \\
\hline agriculture & $\begin{array}{c}0.0731 * * * \\
(0.0147)\end{array}$ & $\begin{array}{c}0.0745 * * * \\
(0.0152)\end{array}$ & $\begin{array}{c}0.0738 * * * \\
(0.0148)\end{array}$ & $\begin{array}{c}0.0575 * * * \\
(0.0127)\end{array}$ & $\begin{array}{c}0.0565 * * * \\
(0.0118)\end{array}$ & $\begin{array}{c}0.0394 * * * \\
(0.00732)\end{array}$ & $\begin{array}{c}0.0362 * * * \\
(0.00808)\end{array}$ & $\begin{array}{c}0.0359 * * * \\
(0.00805)\end{array}$ & $\begin{array}{c}0.0364 * * * \\
(0.00818)\end{array}$ & $\begin{array}{c}0.0363 * * * \\
(0.00812)\end{array}$ \\
\hline gather/hunt/fish & $\begin{array}{c}0.0708^{* * * *} \\
(0.0155)\end{array}$ & $\begin{array}{c}0.0711 * * * \\
(0.0156)\end{array}$ & $\begin{array}{c}0.0676^{* * * *} \\
(0.0151)\end{array}$ & $\begin{array}{c}0.0493 * * * \\
(0.0122)\end{array}$ & $\begin{array}{c}0.0482 * * * \\
(0.0119)\end{array}$ & $\begin{array}{l}0.0179 * * \\
(0.00725)\end{array}$ & $\begin{array}{l}0.0166^{* *} \\
(0.00749)\end{array}$ & $\begin{array}{l}0.0152 * * \\
(0.00757)\end{array}$ & $\begin{array}{l}0.0163 * * \\
(0.00763)\end{array}$ & $\begin{array}{c}0.0143 * \\
(0.00734)\end{array}$ \\
\hline $\ln \left(1+\right.$ slaves per $\left.\mathrm{km}^{2}\right)$ & & $\begin{array}{l}-0.00258 \\
(0.00512)\end{array}$ & $\begin{array}{l}-0.00426 \\
(0.00515)\end{array}$ & $\begin{array}{l}-0.000876 \\
(0.00403)\end{array}$ & $\begin{array}{l}-0.00320 \\
(0.00379)\end{array}$ & & $\begin{array}{c}0.00506 \\
(0.00383)\end{array}$ & $\begin{array}{c}0.00453 \\
(0.00376)\end{array}$ & $\begin{array}{c}0.00468 \\
(0.00379)\end{array}$ & $\begin{array}{c}0.00359 \\
(0.00376)\end{array}$ \\
\hline $\ln (1+$ Christian missi & ons per $\mathrm{km}^{2}$ ) & & $\begin{array}{c}0.212^{* *} \\
(0.103)\end{array}$ & $\begin{array}{c}0.145 \\
(0.0896)\end{array}$ & $\begin{array}{c}0.0903 \\
(0.0910)\end{array}$ & & & $\begin{array}{c}0.0845^{* *} \\
(0.0341)\end{array}$ & $\begin{array}{c}0.0817 * * \\
(0.0345)\end{array}$ & $\begin{array}{l}0.0570 * \\
(0.0340)\end{array}$ \\
\hline Muslim & & & & $\begin{array}{c}-0.418 * * * \\
(0.0278)\end{array}$ & $\begin{array}{c}-0.410 * * * \\
(0.0279)\end{array}$ & & & & $\begin{array}{l}0.00501 \\
(0.0238)\end{array}$ & $\begin{array}{l}0.00785 \\
(0.0236)\end{array}$ \\
\hline Other Religions & & & & $\begin{array}{c}-0.416 * * * \\
(0.0388)\end{array}$ & $\begin{array}{c}-0.413 * * * \\
(0.0391)\end{array}$ & & & & $\begin{array}{c}-0.168 * * * \\
(0.0184)\end{array}$ & $\begin{array}{c}-0.168 * * * \\
(0.0188)\end{array}$ \\
\hline distance to the capita & city & & & & $\begin{array}{c}-0.0963 * \\
(0.0577)\end{array}$ & & & & & $\begin{array}{c}-0.101 * * * \\
(0.0310)\end{array}$ \\
\hline distance to the coast & & & & & $\begin{array}{c}-0.000163 * * \\
(0.0000707)\end{array}$ & & & & & $\begin{array}{l}-0.0000291 \\
0.0000384)\end{array}$ \\
\hline Simple Controls & Yes & Yes & Yes & Yes & Yes & Yes & Yes & Yes & Yes & Yes \\
\hline Coordinates FE & Yes & Yes & Yes & Yes & Yes & Yes & Yes & Yes & Yes & Yes \\
\hline Observations & 285,155 & 284,654 & 284,654 & 284,208 & 283,264 & 269,929 & 269,428 & 269,428 & 268,987 & 268,043 \\
\hline $\mathrm{R}^{2}$ & .506 & .507 & .507 & .513 & .514 & .676 & .676 & .676 & .676 & .676 \\
\hline
\end{tabular}

Standard errors in parentheses, clustered at the ethnicity level. Simple controls include age, age squared, a female dummy, and a mover dummy; The default group in columns 4 and 9 are Christians. Distance to capital is the distance from one's ancestral homeland to the capital of the country, distance to coast is the distance from one's ancestral homeland to the nearest coast, $\ln \left(1+\right.$ slaves per $\left.\mathrm{km}^{2}\right)$ is calculated using the total number of slaves per square kilometer in one's ancestral homeland, and similarly $\ln \left(1+\right.$ missions per $\left.\mathrm{km}^{2}\right)$ is computed using the total number of missions per square kilometer in one's ancestral homeland; *** $\mathrm{p}<0.01, * * \mathrm{p}<0.05,{ }^{*} \mathrm{p}<0.1$ 
Table 12. Violence Toward Women

\begin{tabular}{|c|c|c|c|}
\hline VARIABLES & \multicolumn{3}{|c|}{$\begin{array}{l}\text { First Principal Component of Whether it is Justified } \\
\text { to Beat One's Wife }\end{array}$} \\
\hline agriculture & $\begin{array}{l}-0.0285^{* *} \\
(0.0135)\end{array}$ & $\begin{array}{l}-0.0265^{* *} \\
(0.0124)\end{array}$ & $\begin{array}{l}-0.0229 * \\
(0.0116)\end{array}$ \\
\hline gather/hunt/fish & $\begin{array}{c}-0.016 \\
(0.0125)\end{array}$ & $\begin{array}{l}-0.0135 \\
(0.0122)\end{array}$ & $\begin{array}{c}-0.0087 \\
(0.0120)\end{array}$ \\
\hline Muslim & & & $\begin{array}{l}0.1113 * * * \\
(0.0217)\end{array}$ \\
\hline Other Religions & & & $\begin{array}{l}0.1401 * * * \\
(0.0355)\end{array}$ \\
\hline Simple Controls & Yes & Yes & Yes \\
\hline Coordinates FE & No & Yes & Yes \\
\hline Occupation FE & Yes & Yes & Yes \\
\hline Observations & 61,495 & 61,495 & 61,433 \\
\hline $\mathrm{R}^{2}$ & 0.250 & .254 & .254 \\
\hline
\end{tabular}

Standard errors in parentheses are clustered at the Atlas level; The sample consists of males only. Simple controls include age, age squared, and a mover indicator; The dep. Var. is the first principal component on a series of questions on whether it is justified to beat one's wife; *** $\mathrm{p}<0.01,{ }^{* *} \mathrm{p}<0.05$, $* \mathrm{p}<0.1$ 


\begin{tabular}{|c|c|c|c|c|c|c|c|}
\hline & 1 & 2 & 3 & 4 & 5 & 6 & 7 \\
\hline VARIABLES & $\begin{array}{c}\text { Group's } \\
\text { Political } \\
\text { Influence }\end{array}$ & $\begin{array}{l}\text { Respondent } \\
\text { is Hostile }\end{array}$ & $\begin{array}{c}\text { Respondent } \\
\text { is Bored }\end{array}$ & $\begin{array}{l}\text { Respondent } \\
\text { is Non- } \\
\text { Cooperative }\end{array}$ & $\begin{array}{l}\text { Respondent } \\
\text { is Impatient }\end{array}$ & $\begin{array}{l}\text { Respondent } \\
\text { is Suspicious }\end{array}$ & $\begin{array}{l}\text { Respondent } \\
\text { is Dishonest }\end{array}$ \\
\hline agriculture & $\begin{array}{c}-0.0885 * * * \\
(0.0279)\end{array}$ & $\begin{array}{l}-0.0054 \\
(0.0040)\end{array}$ & $\begin{array}{c}-0.0167 * * \\
(0.0066)\end{array}$ & $\begin{array}{l}-0.0137 * \\
(0.0076)\end{array}$ & $\begin{array}{c}-0.0177 * * \\
(0.0086)\end{array}$ & $\begin{array}{l}-0.0106 \\
(0.0070)\end{array}$ & $\begin{array}{c}-0.0147 * * \\
(0.0057)\end{array}$ \\
\hline gather/hunt/fish & $\begin{array}{c}0.0170 \\
(0.0264)\end{array}$ & $\begin{array}{l}-0.0017 \\
(0.0037)\end{array}$ & $\begin{array}{l}-0.0096 \\
(0.0060)\end{array}$ & $\begin{array}{l}-0.0024 \\
(0.0056)\end{array}$ & $\begin{array}{l}-0.0136^{*} \\
(0.0075)\end{array}$ & $\begin{array}{c}0.0035 \\
(0.0061)\end{array}$ & $\begin{array}{l}-0.0011 \\
(0.0042)\end{array}$ \\
\hline Simple Controls & Yes & Yes & Yes & Yes & Yes & Yes & Yes \\
\hline Coordinates FE & Yes & Yes & Yes & Yes & Yes & Yes & Yes \\
\hline Interviewer FE & No & Yes & Yes & Yes & Yes & Yes & Yes \\
\hline $\mathrm{R}^{2}$ & 0.339 & 0.368 & 0.363 & 0.349 & 0.354 & 0.397 & 0.43 \\
\hline Observations & 19480 & 20851 & 20863 & 20867 & 20865 & 20869 & 20867 \\
\hline
\end{tabular}

Standard errors in parentheses are clustered at the Atlas level; Simple controls include age, age squared, a female dummy and a mover indicator; Group's political influence variable captures the respondents perception whether his/her own group has more influence politically compared to other groups. Higher values indicate lesser influence; $* * * \mathrm{p}<0.01, * * \mathrm{p}<0.05, * \mathrm{p}<0.1$

Table 14: Ancestral Lifeways Education, Political Representation and Attitudes

\begin{tabular}{|c|c|c|c|c|c|}
\hline VARIABLES & $\begin{array}{c}1 \\
\text { Education }\end{array}$ & $\begin{array}{c}2 \\
\text { Education }\end{array}$ & $\begin{array}{c}3 \\
\text { Education }\end{array}$ & $\begin{array}{c}4 \\
\text { Education }\end{array}$ & $\begin{array}{c}5 \\
\text { Education }\end{array}$ \\
\hline agriculture & $\begin{array}{l}0.0164 * * \\
(0.0077)\end{array}$ & $\begin{array}{l}0.0180 * * \\
(0.0078)\end{array}$ & $\begin{array}{l}0.0159 * * \\
(0.0077)\end{array}$ & $\begin{array}{l}0.0165 * * \\
(0.0076)\end{array}$ & $\begin{array}{l}0.0145^{*} \\
(0.0076)\end{array}$ \\
\hline gather/hunt/fish & $\begin{array}{c}0.0101 \\
(0.0076)\end{array}$ & $\begin{array}{c}0.0099 \\
(0.0073)\end{array}$ & $\begin{array}{c}0.0097 \\
(0.0072)\end{array}$ & $\begin{array}{c}0.0101 \\
(0.0071)\end{array}$ & $\begin{array}{c}0.01 \\
(0.0070)\end{array}$ \\
\hline $\begin{array}{l}\text { Simple Controls } \\
\text { Coordinates FE }\end{array}$ & $\begin{array}{l}\text { Yes } \\
\text { Yes }\end{array}$ & $\begin{array}{l}\text { Yes } \\
\text { Yes }\end{array}$ & $\begin{array}{l}\text { Yes } \\
\text { Yes }\end{array}$ & $\begin{array}{l}\text { Yes } \\
\text { Yes }\end{array}$ & $\begin{array}{l}\text { Yes } \\
\text { Yes }\end{array}$ \\
\hline Interviewer FE & No & Yes & Yes & Yes & Yes \\
\hline $\begin{array}{l}\text { Personality Traits } \\
\text { Group's Political }\end{array}$ & No & No & Yes & No & Yes \\
\hline Influence & No & No & No & Yes & Yes \\
\hline $\mathrm{R}^{2}$ & 0.55 & 0.576 & 0.582 & 0.576 & 0.582 \\
\hline Observations & 19422 & 19422 & 19422 & 19422 & 19422 \\
\hline
\end{tabular}

Standard errors in parentheses are clustered at the Atlas level; Simple controls include age, age squared, a female dummy, and a mover dummy; In Columns 2-5 we add interviewer fixed effects; in column 3 we control for the respondent's perception of own ethnic influence in politics as well as the attitudes of each respondent as recorded by the interviewer regarding whether the respondent is bored, non-cooperative, suspicious, impatient and dishonest. In Column 4 we control for the respondent's perception of own ethnic influence in politics. In column 5 we control for both political influence and personality traits. The education variable is the $\log (1+$ educational category). The latter takes 10 values corresponding to: $0=$ No formal schooling, $1=$ Informal schooling (including Koranic schooling), $2=$ Some primary schooling, 3=Primary school completed, 4=Some secondary school/ High school, $5=$ Secondary school completed/High school, 6=Post-secondary qualifications, other than university e.g. a diploma or degree from a technical/polytechnic/college, $7=$ Some university, $8=$ University completed, 9=Post-graduate. $* * * \mathrm{p}<0.01, * * \mathrm{p}<0.05, * \mathrm{p}<0.1$ 


\section{Appendix Figures $1 \mathrm{a}$ and $\mathbf{1 b}$}

The Role of Pre-Colonial Agricultural Dependence on Education and Wealth by 5-Year Birth Cohorts

$1 a$

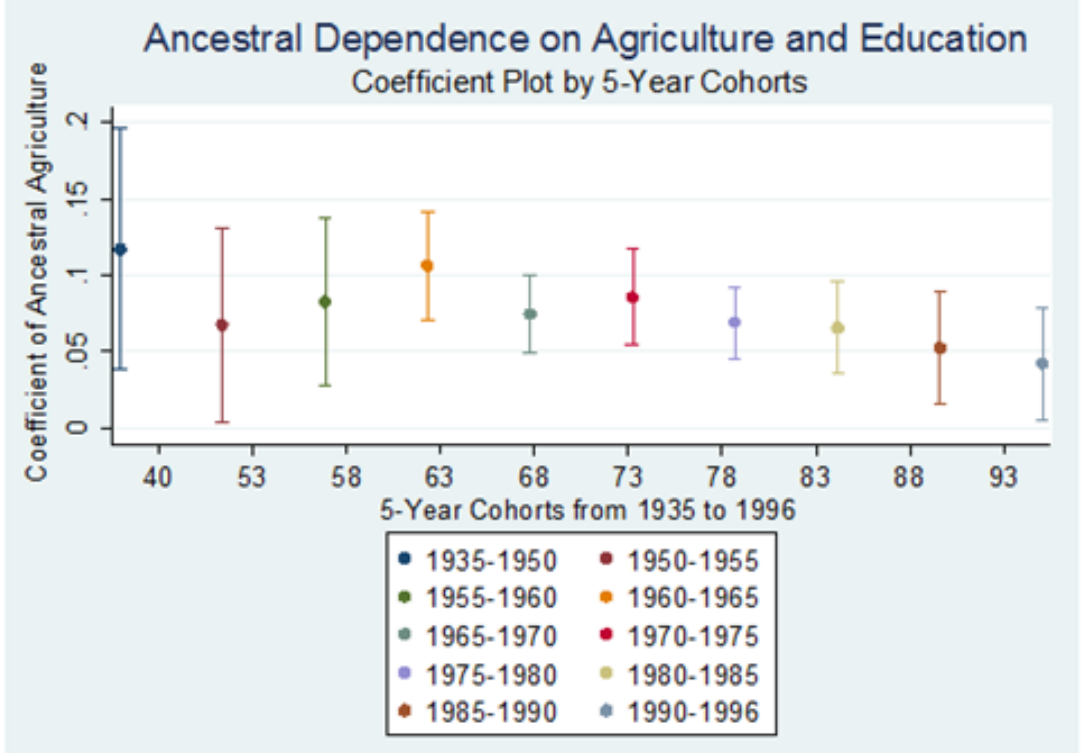

$1 b$

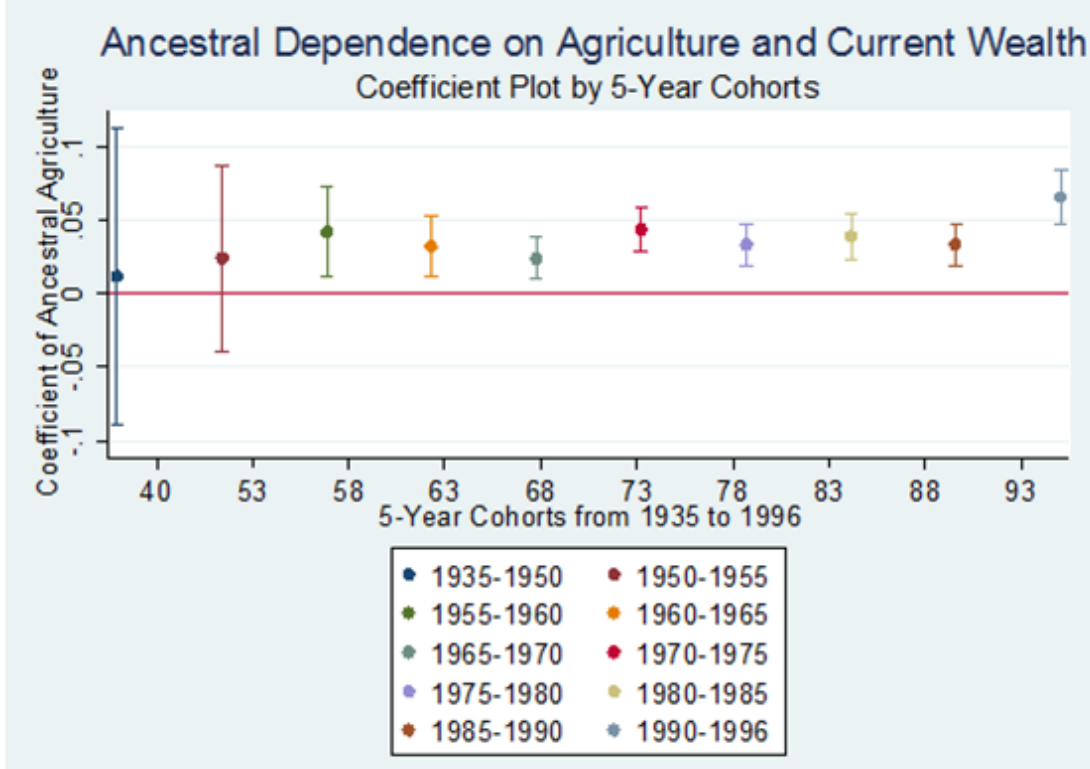


Appendix Table 1: Matching Ethnicities in the DHS to Murdock Map and Atlas

\begin{tabular}{|l|l|l|l|l|}
\hline Method & $\begin{array}{l}\text { Atlas } \\
\text { Percent }\end{array}$ & $\begin{array}{l}\text { Atlas Cum. } \\
\text { Percent }\end{array}$ & $\begin{array}{l}\text { Map } \\
\text { Percent }\end{array}$ & $\begin{array}{l}\text { Map Cum. } \\
\text { Percent }\end{array}$ \\
\hline Direct Match & 58.41 & 58.41 & 66.7 & 66.7 \\
\hline Afrobarometer & 4.43 & 62.84 & 10.92 & 77.61 \\
\hline $\begin{array}{l}\text { Ethnologue/Joshua Alternate } \\
\text { Name }\end{array}$ & 11.44 & 74.28 & 6.33 & 83.95 \\
\hline Ethnologue/Joshua superset & 2.53 & 76.81 & 2.27 & 86.21 \\
\hline Ethnologue/Joshua subset & 5.05 & 81.86 & 4.49 & 90.7 \\
\hline Other Source (e.g. Wikipedia) & 0.53 & 82.40 & 0.82 & 91.53 \\
\hline Other Source, not sure & 5.47 & 87.87 & 0.28 & 91.8 \\
\hline Ethnologue/Joshua related & 0.08 & 87.95 & 0.08 & 91.88 \\
\hline Nunn and Wantchekon (2011) & 2.55 & 90.50 & 0.78 & 92.66 \\
\hline $\begin{array}{l}\text { Michalopoulos } \\
\text { Papaioannou (2013) }\end{array}$ & 0.81 & 91.31 & 0.95 & 93.61 \\
\hline Not Matched & 8.69 & 100.00 & 6.39 & 100 \\
\hline
\end{tabular}

\section{Description of the Matching Methodologies:}

1) Direct match: the DHS ethnicity name is the same as the name used in the Murdock source (Atlas or Map).

2) Afrobarometer match: Nunn and Wantchekon (2011) create matches between the Afrobarometer Round 3 ethnicities (http://www.afrobarometer.org) and the Murdock names. Using the Nunn and Wantchekon (2011) data, we were able to match more DHS ethnicities to Murdock names through Afrobarometer names.

3) Ethnologue/Joshua Alternate Name: the DHS ethnicity name and the Atlas name are "alternative names" according to either Ethnologue (http://www.ethnologue.com/) or Joshua Project (http://joshuaproject.net/ ).

4) Ethnologue/Joshua superset: In Joshua or Ethnologue, we find a matching Atlas or Map name that appears as a superset (i.e., containing set) of our target DHS ethnicity. For example, if the group "American English" appears in the DHS and Ethnologue describes this group as a subset of "English," which appears in the Murdock data. 
5) Ethnologue/Joshua subset: In Joshua or Ethnologue we find a matching Atlas or Map name that appears as a subset of the DHS ethnicity that we want to match. For example, if "Chinese"appeared in the DHS and "Mandarin" appeared in the Murdock data, and if Ethnologue informed us the latter was a subset of the former.

6) Other source (e.g., Wikipedia)

7) Other source (e.g., Wikipedia) not sure: used in cases where the information from other sources left questions about the quality of the match.

8) Ethnologue/joshua related: we find a group that is related to our target ethnic group, according to either Ethnologue or Joshua Project.

9) Nunn and Wantchekon (2011): we referred to a do file used in this paper that resolves the discrepancies in the Map and Atlas names of the same ethnicity

10) Michalopoulos and Papaioannou (2013) 
Appendix Table 2: Summary Statistics in the DHS - All Individuals

\begin{tabular}{lccccc}
\hline Variable & Obs & Mean & Std. Dev. & Min & Max \\
\hline agriculture & 285,163 & 5.861 & 1.511 & 0 & 9 \\
pastoralism & 285,163 & 2.338 & 1.718 & 0 & 9 \\
fishing & 285,163 & 0.764 & 0.814 & 0 & 4 \\
hunting & 285,163 & 0.707 & 0.733 & 0 & 7 \\
gathering & 285,163 & 0.325 & 0.543 & 0 & 3 \\
gather/hunt/fish & 285,163 & 1.796 & 1.329 & 0 & 10 \\
education & 285,218 & 1.356 & 1.472 & 0 & 5 \\
wealth & 269,992 & 3.119 & 1.437 & 1 & 5 \\
Christian & 284,780 & 0.527 & 0.499 & 0 & 1 \\
Muslim & 284,780 & 0.412 & 0.492 & 0 & 1 \\
ln(1+slaves per km $\left.{ }^{2}\right)$ & 284,725 & 4.339 & 3.457 & 0 & 10.540 \\
ln(1+missions per km $\left.{ }^{2}\right)$ & 284,725 & 0.105 & 0.182 & 0 & 1.287 \\
polygyny & 281,013 & 0.488 & 0.500 & 0 & 1 \\
clans & 260,806 & 0.213 & 0.409 & 0 & 1 \\
jurisdictional hierarchy at the local level & 269,451 & 3.158 & 0.638 & 2 & 4 \\
jurisdictional hierarchy above the local level & 269,451 & 2.719 & 0.903 & 1 & 5 \\
class stratification dummy & 258,254 & 0.685 & 0.464 & 0 & 1 \\
elections & 217,906 & 0.188 & 0.391 & 0 & 1 \\
slavery & 269,961 & 0.812 & 0.390 & 0 & 1 \\
property & 256,549 & 0.947 & 0.224 & 0 & 1 \\
\hline
\end{tabular}


Appendix Table 3. Benchmark: DHS Regressions within Villages/Towns with Mostly

Categories Disaggregated

\begin{tabular}{|c|c|c|c|c|c|c|}
\hline VARIABLES & $\begin{array}{c}1 \\
\text { Education } \\
\end{array}$ & $\begin{array}{c}2 \\
\text { Education } \\
\end{array}$ & $\begin{array}{c}3 \\
\text { Education } \\
\end{array}$ & $\begin{array}{c}4 \\
\text { Wealth } \\
\end{array}$ & $\begin{array}{c}5 \\
\text { Wealth } \\
\end{array}$ & $\begin{array}{c}6 \\
\text { Wealth } \\
\end{array}$ \\
\hline Mostly Intensive & $0.3059 * *$ & $0.1590 * *$ & $0.1516 * *$ & $0.2838 * *$ & $0.1102 * * *$ & $0.1045 * * *$ \\
\hline Agriculture & $(0.1182)$ & $(0.0738)$ & $(0.0589)$ & $(0.1245)$ & $(0.0413)$ & $(0.0383)$ \\
\hline Mostly Extensive & $0.2844 * *$ & $0.1422 * *$ & $0.1438 * *$ & $0.3311 * * *$ & $0.1265 * * *$ & $0.1226 * * *$ \\
\hline Agriculture & $(0.1158)$ & $(0.0713)$ & $(0.0585)$ & $(0.1181)$ & $(0.0407)$ & $(0.0382)$ \\
\hline Mostly Agriculture & $0.3225 * * *$ & $0.1536^{*}$ & $0.1576^{* *}$ & $0.4353 * * *$ & $0.1262 * *$ & $0.1180 * *$ \\
\hline unknown Source & $(0.1231)$ & $(0.0811)$ & $(0.0670)$ & $(0.1240)$ & $(0.0570)$ & $(0.0527)$ \\
\hline \multirow[t]{2}{*}{ Mixed Dependence } & 0.0654 & $(0.0099)$ & $(0.0125)$ & 0.1374 & 0.0590 & 0.0489 \\
\hline & $(0.1147)$ & $(0.0717)$ & $(0.0588)$ & $(0.1221)$ & $(0.0422)$ & $(0.0395)$ \\
\hline \multirow[t]{2}{*}{ Mostly Hunting } & $-1.5689 * * *$ & & & $-1.7784 * * *$ & & \\
\hline & $(0.1194)$ & & & $(0.1176)$ & & \\
\hline \multirow[t]{2}{*}{ urban } & $0.9295 * * *$ & & & $1.6464 * * *$ & & \\
\hline & $(0.0351)$ & & & $(0.0473)$ & & \\
\hline Simple Controls & Yes & Yes & Yes & Yes & Yes & Yes \\
\hline $\begin{array}{l}\text { Ethnic Homeland- } \\
\text { Country FE }\end{array}$ & Yes & No & No & Yes & No & No \\
\hline Coordinates FE & No & Yes & Yes & No & Yes & Yes \\
\hline Occupation FE & No & No & Yes & No & No & Yes \\
\hline Observations & 285,155 & 285,155 & 285,155 & 269,929 & 269,929 & 269,929 \\
\hline $\mathrm{R}^{2}$ & 0.42 & 0.51 & 0.56 & 0.49 & 0.68 & 0.68 \\
\hline
\end{tabular}

Standard errors in parentheses are clustered at the ethnicity level, simple controls include age, age squared and a female dummy. Omitted category mostly pastoralism.

$* * * \mathrm{p}<0.01, * * \mathrm{p}<0.05, * \mathrm{p}<0.1$ 
Appendix Table 4. Benchmark: DHS Regressions within Villages/Towns

\begin{tabular}{|c|c|c|c|c|c|c|}
\hline VARIABLES & $\begin{array}{c}1 \\
\text { Education }\end{array}$ & $\begin{array}{c}2 \\
\text { Education }\end{array}$ & $\begin{array}{c}3 \\
\text { Education }\end{array}$ & $\begin{array}{c}4 \\
\text { Wealth }\end{array}$ & $\begin{array}{c}5 \\
\text { Wealth }\end{array}$ & $\begin{array}{c}6 \\
\text { Wealth }\end{array}$ \\
\hline agriculture & $\begin{array}{c}0.1036 * * * \\
(0.0216)\end{array}$ & $\begin{array}{c}0.0763 * * * \\
(0.0157)\end{array}$ & $\begin{array}{c}0.0725 * * * \\
(0.0140)\end{array}$ & $\begin{array}{c}0.0983 * * * \\
(0.0236)\end{array}$ & $\begin{array}{c}0.0406 * * * \\
(0.0079)\end{array}$ & $\begin{array}{c}0.0397 * * * \\
(0.0078)\end{array}$ \\
\hline gathering & $\begin{array}{l}0.0526^{*} \\
(0.0311)\end{array}$ & $\begin{array}{c}0.0166 \\
(0.0227)\end{array}$ & $\begin{array}{c}0.0167 \\
(0.0197)\end{array}$ & $\begin{array}{l}-0.0143 \\
(0.0284)\end{array}$ & $\begin{array}{l}-0.0071 \\
(0.0107)\end{array}$ & $\begin{array}{l}-0.0042 \\
(0.0102)\end{array}$ \\
\hline hunting & $\begin{array}{c}0.1058 * * * \\
(0.0326)\end{array}$ & $\begin{array}{c}0.0953 * * * \\
(0.0263)\end{array}$ & $\begin{array}{c}0.0922 * * * \\
(0.0243)\end{array}$ & $\begin{array}{l}0.0683 * * \\
(0.0320)\end{array}$ & $\begin{array}{l}0.0268 * \\
(0.0152)\end{array}$ & $\begin{array}{l}0.0294 * * \\
(0.0149)\end{array}$ \\
\hline fishing & $\begin{array}{c}0.1041 * * * \\
(0.0260)\end{array}$ & $\begin{array}{c}0.0889 * * * \\
(0.0215)\end{array}$ & $\begin{array}{c}0.0846 * * * \\
(0.0193)\end{array}$ & $\begin{array}{c}0.0666 * * * \\
(0.0220)\end{array}$ & $\begin{array}{c}0.0276 * * * \\
(0.0088)\end{array}$ & $\begin{array}{c}0.0275^{* * *} \\
(0.0083)\end{array}$ \\
\hline urban & $\begin{array}{r}0.9201 * * * \\
(0.0358)\end{array}$ & & & $\begin{array}{r}1.6292 * * * \\
(0.0474)\end{array}$ & & \\
\hline Simple Controls & Yes & Yes & Yes & Yes & Yes & Yes \\
\hline $\begin{array}{l}\text { Ethnic Homeland- } \\
\text { Country FE }\end{array}$ & Yes & No & No & Yes & No & No \\
\hline Coordinates FE & No & Yes & Yes & No & Yes & Yes \\
\hline Occupation FE & No & No & Yes & No & No & Yes \\
\hline Observations & 285,155 & 285,155 & 285,155 & 269,929 & 269,929 & 269,929 \\
\hline $\mathrm{R}^{2}$ & 0.418 & 0.507 & 0.559 & 0.489 & 0.676 & 0.681 \\
\hline
\end{tabular}

Standard errors in parentheses are clustered at the ethnicity level, simple controls include age, age squared, a female dummy, and a mover dummy;

$* * * \mathrm{p}<0.01, * * \mathrm{p}<0.05, * \mathrm{p}<0.1$ 
Appendix Table 5 - Panel A. Wealth

\begin{tabular}{|c|c|c|c|c|c|c|c|c|c|c|c|}
\hline COUNTRIES & $\begin{array}{c}(1) \\
\text { Burkina } \\
\text { Faso }\end{array}$ & Benin & Congo, DR & $\begin{array}{c}(4) \\
\text { Central } \\
\text { African } \\
\text { Republic }\end{array}$ & $\begin{array}{c}(5) \\
\text { Cote } \\
\text { d'Ivoire }\end{array}$ & Cameroon & Ethiopia & Ghana & Guinea & Kenya & (11) \\
\hline agriculture & $\begin{array}{c}0.0961 * * * \\
(0.0283)\end{array}$ & $\begin{array}{c}0.1250 * * \\
(0.0370)\end{array}$ & $\begin{array}{c}0.0382 * * \\
(0.0067)\end{array}$ & $\begin{array}{l}-0.1166 \\
(0.0707)\end{array}$ & & $\begin{array}{c}-0.0747 * * * \\
(0.0200)\end{array}$ & $\begin{array}{c}0.0607 * * * \\
(0.0191)\end{array}$ & $\begin{array}{c}0.0521 * * * \\
(0.0119)\end{array}$ & $\begin{array}{l}-0.0740 \\
(0.0490)\end{array}$ & $\begin{array}{c}0.0299 * * \\
(0.0124)\end{array}$ & $\begin{array}{c}0.0290 * * \\
(0.0088)\end{array}$ \\
\hline gather/hunt/fish & $\begin{array}{c}0.0882 * * * \\
(0.0231)\end{array}$ & $\begin{array}{c}0.2629 * * * \\
(0.0585)\end{array}$ & & $\begin{array}{c}-0.1645 * * \\
(0.0688)\end{array}$ & $\begin{array}{c}0.1589 * * \\
(0.0372)\end{array}$ & $\begin{array}{c}-0.0576^{* * *} \\
(0.0165)\end{array}$ & $\begin{array}{c}-0.1279 * * \\
(0.0513)\end{array}$ & $\begin{array}{c}0.0579 * * * \\
(0.0090)\end{array}$ & $\begin{array}{c}0.0154 * \\
(0.0069)\end{array}$ & $\begin{array}{l}-0.0278 \\
(0.0153)\end{array}$ & $\begin{array}{c}0.0025 \\
(0.0104)\end{array}$ \\
\hline Coordinates FE & Yes & Yes & Yes & Yes & Yes & Yes & Yes & Yes & Yes & Yes & Yes \\
\hline Observations & 20,770 & 8,550 & 2,186 & 7,435 & 2,343 & 13,672 & 27,327 & 8,512 & 3,092 & 11,030 & 17,191 \\
\hline $\mathrm{R}^{2}$ & 0.607 & 0.695 & 0.783 & 0.642 & 0.779 & 0.715 & 0.732 & 0.771 & 0.740 & 0.723 & 0.648 \\
\hline
\end{tabular}

Standard errors in parentheses are clustered at the ethnicity level;*** $\mathrm{p}<0.01, * * \mathrm{p}<0.05, * \mathrm{p}<0.1$

Appendix Table 5 - Panel A. Wealth (Continued)

\begin{tabular}{|c|c|c|c|c|c|c|c|c|c|c|}
\hline & (12) & (13) & (14) & (15) & (16) & (17) & (18) & (19) & (20) & (21) \\
\hline COUNTRIES & Malawi & Mozambique & Nigeria & Niger & Namibia & Sierra Leone & Senegal & Togo & Uganda & Zambia \\
\hline agriculture & $\begin{array}{c}0.0265 \\
(0.0456)\end{array}$ & $\begin{array}{c}0.0191 \\
(0.0209)\end{array}$ & $\begin{array}{c}0.0936 * * \\
(0.0324)\end{array}$ & $\begin{array}{c}0.0248 * * \\
(0.0106)\end{array}$ & $\begin{array}{c}-0.0595 \\
(0.0774)\end{array}$ & $\begin{array}{c}0.0556^{* *} \\
(0.0139)\end{array}$ & $\begin{array}{c}0.0808 * * \\
(0.0306)\end{array}$ & $\begin{array}{c}0.4055^{* *} \\
(0.0841)\end{array}$ & $\begin{array}{c}0.0805 * * * \\
(0.0240)\end{array}$ & $\begin{array}{c}0.0373 * * * \\
(0.0124)\end{array}$ \\
\hline gather/hunt/fish & $\begin{array}{l}-0.0059 \\
(0.0364)\end{array}$ & $\begin{array}{c}0.0066 \\
(0.0152)\end{array}$ & $\begin{array}{l}0.0718^{*} \\
(0.0332)\end{array}$ & $\begin{array}{c}0.0329 * * \\
(0.0126)\end{array}$ & $\begin{array}{l}-0.0925 \\
(0.1333)\end{array}$ & $\begin{array}{c}0.0849 \\
(0.0436)\end{array}$ & $\begin{array}{l}-0.0011 \\
(0.0167)\end{array}$ & $\begin{array}{l}0.3957 * \\
(0.1436)\end{array}$ & $\begin{array}{l}0.0723 * \\
(0.0373)\end{array}$ & $\begin{array}{l}0.0232 * \\
(0.0135)\end{array}$ \\
\hline Coordinates FE & Yes & Yes & Yes & Yes & Yes & Yes & Yes & Yes & Yes & Yes \\
\hline Observations & 28,378 & 15,249 & 34,647 & 10,822 & 8,011 & 7,344 & 18,485 & 3,435 & 8,492 & 12,958 \\
\hline $\mathrm{R}^{2}$ & 0.345 & 0.712 & 0.786 & 0.630 & 0.718 & 0.697 & 0.720 & 0.689 & 0.649 & 0.762 \\
\hline
\end{tabular}

Standard errors in parentheses are clustered at the ethnicity level; simple controls include age, age squared, a female dummy, and a mover dummy; $* * * \mathrm{p}<0.01, * * \mathrm{p}<0.05, * \mathrm{p}<0.1$ 
Appendix Table 5 - Panel B. Education

\begin{tabular}{|c|c|c|c|c|c|c|c|c|c|c|c|}
\hline COUNTRIES & $\begin{array}{c}(1) \\
\text { Burkina } \\
\text { Faso }\end{array}$ & Benin & Congo, DR & $\begin{array}{c}(4) \\
\text { Central } \\
\text { African } \\
\text { Republic }\end{array}$ & $\begin{array}{c}\text { Cote } \\
\text { d'Ivoire }\end{array}$ & Cameroon & Ethiopia & Ghana & Guinea & Kenya & (11) \\
\hline agriculture & $\begin{array}{c}0.2267 * * * \\
(0.0481)\end{array}$ & $\begin{array}{c}0.1005 \\
(0.0567)\end{array}$ & $\begin{array}{l}-0.0902 \\
(0.0344)\end{array}$ & $\begin{array}{c}0.2255^{*} \\
(0.1036)\end{array}$ & & $\begin{array}{c}0.1679 * * * \\
(0.0452)\end{array}$ & $\begin{array}{c}0.0356 \\
(0.0468)\end{array}$ & $\begin{array}{c}0.3238 * * * \\
(0.0501)\end{array}$ & $\begin{array}{c}0.1727 * * * \\
(0.0218)\end{array}$ & $\begin{array}{c}0.1377 * * \\
(0.0566)\end{array}$ & $\begin{array}{c}0.0293 \\
(0.0361)\end{array}$ \\
\hline gather/hunt/fish & $\begin{array}{c}0.0448 \\
(0.0399)\end{array}$ & $\begin{array}{l}0.1764 * \\
(0.0807)\end{array}$ & & $\begin{array}{l}0.1886^{*} \\
(0.0961)\end{array}$ & $\begin{array}{c}0.2393 \\
(0.1963)\end{array}$ & $\begin{array}{c}0.1847 * * * \\
(0.0249)\end{array}$ & $\begin{array}{l}-0.0131 \\
(0.1400)\end{array}$ & $\begin{array}{c}0.3900 * * * \\
(0.0549)\end{array}$ & $\begin{array}{l}-0.0274 \\
(0.0185)\end{array}$ & $\begin{array}{l}-0.0490 \\
(0.0384)\end{array}$ & $\begin{array}{c}0.0304 \\
(0.0229)\end{array}$ \\
\hline Coordinates FE & Yes & Yes & Yes & Yes & Yes & Yes & Yes & Yes & Yes & Yes & Yes \\
\hline Observations & 20,763 & 8,550 & 2,186 & 7,435 & 2,343 & 13,672 & 27,327 & 8,512 & 10,847 & 11,030 & 17,191 \\
\hline $\mathrm{R}^{2}$ & 0.361 & 0.366 & 0.432 & 0.412 & 0.274 & 0.510 & 0.442 & 0.402 & 0.357 & 0.367 & 0.303 \\
\hline
\end{tabular}

Standard errors in parentheses are clustered at the ethnicity level; *** $\mathrm{p}<0.01,{ }^{* *} \mathrm{p}<0.05,{ }^{*} \mathrm{p}<0.1$

Appendix Table 5 - Panel B. Education (Continued)

\begin{tabular}{|c|c|c|c|c|c|c|c|c|c|c|}
\hline & (12) & (13) & (14) & $(15)$ & (16) & (17) & (18) & (19) & (20) & $(21)$ \\
\hline COUNTRIES & Malawi & Mozambique & Nigeria & Niger & Namibia & Sierra Leone & Senegal & Togo & Uganda & Zambia \\
\hline agriculture & $\begin{array}{c}-0.0053 \\
(0.0712)\end{array}$ & $\begin{array}{c}0.0338 \\
(0.0336)\end{array}$ & $\begin{array}{c}0.2578 * * * \\
(0.0590)\end{array}$ & $\begin{array}{c}0.0377 * * \\
(0.0117)\end{array}$ & $\begin{array}{c}-0.0210 \\
(0.0870)\end{array}$ & $\begin{array}{c}0.4686^{* * * *} \\
(0.0643)\end{array}$ & $\begin{array}{c}-0.0742 \\
(0.0641)\end{array}$ & $\begin{array}{l}0.2219^{*} \\
(0.0878)\end{array}$ & $\begin{array}{c}0.0654 \\
(0.0407)\end{array}$ & $\begin{array}{c}0.0154 \\
(0.0492)\end{array}$ \\
\hline gather/hunt/fish & $\begin{array}{l}-0.0440 \\
(0.0678)\end{array}$ & $\begin{array}{l}0.0796^{*} \\
(0.0346)\end{array}$ & $\begin{array}{c}0.2210^{* * *} \\
(0.0655)\end{array}$ & $\begin{array}{l}0.0606^{*} \\
(0.0317)\end{array}$ & $\begin{array}{c}-0.0444 \\
(0.1679)\end{array}$ & $\begin{array}{l}0.3953 * \\
(0.1355)\end{array}$ & $\begin{array}{c}0.0846^{* * *} \\
(0.0162)\end{array}$ & $\begin{array}{l}0.2913 * \\
(0.0917)\end{array}$ & $\begin{array}{c}0.0334 \\
(0.0727)\end{array}$ & $\begin{array}{l}-0.0213 \\
(0.0240)\end{array}$ \\
\hline Coordinates FE & Yes & Yes & Yes & Yes & Yes & Yes & Yes & Yes & Yes & Yes \\
\hline Observations & 28,378 & 15,249 & 34,647 & 10,822 & 8,011 & 7,344 & 18,485 & 10,913 & 8,492 & 12,958 \\
\hline $\mathrm{R}^{2}$ & 0.252 & 0.390 & 0.615 & 0.347 & 0.305 & 0.373 & 0.371 & 0.408 & 0.338 & 0.364 \\
\hline
\end{tabular}

Standard errors in parentheses are clustered at the ethnicity level; simple controls include age, age squared, a female dummy, and a mover dummy; $* * * \mathrm{p}<0.01, * * \mathrm{p}<0.05, * \mathrm{p}<0.1$ 
Appendix Table 6: Benchmark at Various Subsets

\begin{tabular}{lcccccc}
\hline \multirow{2}{*}{ VARIABLES } & 1 & 2 & 3 & 4 & 5 & 6 \\
& Education & Education & Education & Wealth & Wealth & Wealth \\
\hline & \multicolumn{7}{c}{ Panel A: Countries without Any Predominantly Pastoral Ethnicity } \\
\cline { 2 - 7 } agriculture & $0.1562^{* * *}$ & $0.1066^{* * *}$ & $0.1009^{* * *}$ & $0.1453^{* * *}$ & $0.0672^{* * *}$ & $0.0661^{* * *}$ \\
& $(0.0268)$ & $(0.0226)$ & $(0.0208)$ & $(0.0211)$ & $(0.0106)$ & $(0.0107)$ \\
gather/hunt/fish & $0.1292^{* * *}$ & $0.0945^{* * *}$ & $0.0908^{* * *}$ & $0.0913 * * *$ & $0.0356^{* * *}$ & $0.0377 * * *$ \\
& $(0.0306)$ & $(0.0249)$ & $(0.0232)$ & $(0.0204)$ & $(0.0125)$ & $(0.0122)$ \\
Observations & 189000 & 189000 & 189000 & 173000 & 173000 & 173000 \\
$\mathrm{R}^{2}$ & 0.421 & 0.510 & 0.558 & 0.470 & 0.663 & 0.669 \\
\hline
\end{tabular}

Panel B: Focus on Countries in which Groups with Larger Pre-colonial Dependence on Agriculture are Less Populous Today

\begin{tabular}{lcccccc} 
agriculture & $0.1199 * * *$ & $0.0993 * * *$ & $0.0897 * *$ & $0.1113 * * *$ & $0.0781 * * *$ & $0.0800 * * *$ \\
gather/hunt/fish & $(0.0202)$ & $(0.0187)$ & $(0.0162)$ & $(0.0277)$ & $(0.0233)$ & $(0.0237)$ \\
& $\begin{array}{c}0.0731 * * * \\
(0.0213)\end{array}$ & $\begin{array}{l}0.0686^{* * *} \\
(0.0227)\end{array}$ & $\begin{array}{c}0.0655^{* * *} \\
(0.0209)\end{array}$ & $\begin{array}{l}0.0795^{* *} \\
(0.0302)\end{array}$ & $\begin{array}{c}0.0452 \\
(0.0285)\end{array}$ & $\begin{array}{c}0.0532 * \\
(0.0277)\end{array}$ \\
$\begin{array}{l}\text { Simple Controls } \\
\text { Country-Ethnic }\end{array}$ & Yes & Yes & Yes & Yes & Yes & Yes \\
Homeland FE & Yes & No & No & Yes & No & No \\
Coordinates FE & No & Yes & Yes & No & Yes & Yes \\
Occupation FE & No & No & Yes & No & No & Yes \\
Observations & 86886 & 86886 & 86886 & 71660 & 71660 & 71660 \\
$\mathrm{R}^{2}$ & 0.299 & 0.381 & 0.453 & 0.357 & 0.528 & 0.539 \\
\hline
\end{tabular}

Standard errors in parentheses are clustered at the ethnicity level; simple controls include age, age squared, a female dummy, and a mover dummy; ${ }^{* * *} \mathrm{p}<0.01,{ }^{* *} \mathrm{p}<0.05,{ }^{*} \mathrm{p}<0.1$ 
Appendix Table 7: DHS Regressions within Villages/Towns Controlling Flexibly for How Long Each Individual Resides in her Current Location

\begin{tabular}{|c|c|c|c|c|c|c|}
\hline VARIABLES & $\begin{array}{c}1 \\
\text { Education }\end{array}$ & $\begin{array}{c}2 \\
\text { Education }\end{array}$ & $\begin{array}{c}3 \\
\text { Education }\end{array}$ & $\begin{array}{c}4 \\
\text { Wealth }\end{array}$ & $\begin{array}{c}5 \\
\text { Wealth }\end{array}$ & $\begin{array}{c}6 \\
\text { Wealth }\end{array}$ \\
\hline agriculture & $\begin{array}{c}0.1307 * * * \\
(0.0199)\end{array}$ & $\begin{array}{c}0.0899 * * * \\
(0.0158)\end{array}$ & $\begin{array}{c}0.0889 * * * \\
(0.0145)\end{array}$ & $\begin{array}{c}0.0771 * * * \\
(0.0164)\end{array}$ & $\begin{array}{c}0.0211 * * * \\
(0.0080)\end{array}$ & $\begin{array}{c}0.0204 * * * \\
(0.0077)\end{array}$ \\
\hline gather/hunt/fish & $\begin{array}{c}0.1138 * * * \\
(0.0212)\end{array}$ & $\begin{array}{c}0.0781 * * * \\
(0.0196)\end{array}$ & $\begin{array}{c}0.0786 * * * \\
(0.0185)\end{array}$ & $\begin{array}{c}0.0490 * * * \\
(0.0156)\end{array}$ & $\begin{array}{c}0.0059 \\
(0.0093)\end{array}$ & $\begin{array}{c}0.0071 \\
(0.0086)\end{array}$ \\
\hline urban & $\begin{array}{c}0.8363 * * * \\
(0.0322)\end{array}$ & & & $\begin{array}{c}1.5770 * * * \\
(0.0629)\end{array}$ & & \\
\hline Simple Controls & Yes & Yes & Yes & Yes & Yes & Yes \\
\hline $\begin{array}{l}\text { Ethnic Homeland- } \\
\text { Country FE }\end{array}$ & Yes & No & No & Yes & No & No \\
\hline Coordinates FE & No & Yes & Yes & No & Yes & Yes \\
\hline Occupation FE & No & No & Yes & No & No & Yes \\
\hline Observations & 192,367 & 192,367 & 192,367 & 177,176 & 177,176 & 177,176 \\
\hline $\mathrm{R}^{2}$ & 0.441 & 0.525 & 0.568 & 0.482 & 0.665 & 0.670 \\
\hline
\end{tabular}

Standard errors in parentheses are clustered at the ethnicity level, simple controls include age, age squared, a female dummy, and a mover dummy; We add a dummy for each entry in the mv104 variable which reflects "The years lived in place of residence". It ranges from 0 years to having always lived in the same residence; ${ }^{* * *} \mathrm{p}<0.01,{ }^{* *} \mathrm{p}<0.05, * \mathrm{p}<0.1$

Appendix Table 8: Heterogeneity by Dominant Lifeway of Current Homeland

\begin{tabular}{|c|c|c|c|c|c|c|}
\hline Dep. Variables & $\begin{array}{c}1 \\
\text { Education } \\
\end{array}$ & $\begin{array}{c}2 \\
\text { Education }\end{array}$ & $\begin{array}{c}3 \\
\text { Education } \\
\end{array}$ & $\begin{array}{c}4 \\
\text { Wealth } \\
\end{array}$ & $\begin{array}{c}5 \\
\text { Wealth } \\
\end{array}$ & $\begin{array}{c}6 \\
\text { Wealth } \\
\end{array}$ \\
\hline $\begin{array}{l}\text { Historical Lifeway } \\
\text { of the Current } \\
\text { Homeland }\end{array}$ & $\begin{array}{c}\text { Mostly } \\
\text { Agricultur } \\
\mathrm{e} \\
\end{array}$ & $\begin{array}{l}\text { Mostly } \\
\text { Pastoral }\end{array}$ & Mixed & $\begin{array}{c}\text { Mostly } \\
\text { Agriculture }\end{array}$ & $\begin{array}{l}\text { Mostly } \\
\text { Pastoral }\end{array}$ & Mixed \\
\hline agriculture & $\begin{array}{c}0.0900 * * * \\
(0.0144)\end{array}$ & $\begin{array}{c}0.0520 \\
(0.0335)\end{array}$ & $\begin{array}{c}0.0116 \\
(0.0313)\end{array}$ & $\begin{array}{c}0.0487 * * * \\
(0.0076)\end{array}$ & $\begin{array}{c}0.0472 * * \\
(0.0199)\end{array}$ & $\begin{array}{c}0.0637 * * \\
(0.0252)\end{array}$ \\
\hline gather/hunt/fish & $\begin{array}{c}0.0807 * * * \\
(0.0163)\end{array}$ & $\begin{array}{c}0.1003 \\
(0.0621)\end{array}$ & $\begin{array}{l}0.0525 * * \\
(0.0211)\end{array}$ & $\begin{array}{c}0.0255^{* * *} * \\
(0.0078)\end{array}$ & $\begin{array}{l}0.0758 * * \\
(0.0359)\end{array}$ & $\begin{array}{c}0.0114 \\
(0.0207)\end{array}$ \\
\hline Simple Controls & Yes & Yes & Yes & Yes & Yes & Yes \\
\hline Coordinates FE & Yes & Yes & Yes & Yes & Yes & Yes \\
\hline Observations & 215,196 & 9,726 & 7,319 & 205,681 & 9,726 & 5,166 \\
\hline $\mathrm{R}^{2}$ & 0.501 & 0.536 & 0.634 & 0.658 & 0.748 & 0.787 \\
\hline
\end{tabular}

Standard errors in parentheses are clustered at the ethnicity level; simple controls include age, age squared, a female dummy, and a mover dummy; $* * * \mathrm{p}<0.01,{ }^{* *} \mathrm{p}<0.05,{ }^{*} \mathrm{p}<0.1$ 
Appendix Table 9: Summary Statistics for the Afrobarometer Round 4 Variables

\begin{tabular}{|c|c|c|c|c|c|}
\hline Variable & Obs & Mean & Std. Dev. & Min & Max \\
\hline education & 21578 & 3.18 & 2.01 & 0 & 9 \\
\hline group's political influence & 20139 & 3.11 & 1.05 & 1 & 5 \\
\hline respondent hostile & 21570 & 1.12 & 0.34 & 1 & 3 \\
\hline respondent bored & 21582 & 1.22 & 0.46 & 1 & 3 \\
\hline respondent non-cooperative & 21586 & 1.17 & 0.40 & 1 & 3 \\
\hline respondent impatient & 21582 & 1.23 & 0.49 & 1 & 3 \\
\hline respondent suspicious & 21588 & 1.29 & 0.55 & 1 & 3 \\
\hline respondent dishonest & 21584 & 1.23 & 0.46 & 1 & 3 \\
\hline agriculture & 21608 & 5.74 & 1.32 & 0 & 9 \\
\hline hunter/gather/fish & 21608 & 1.96 & 1.21 & 0 & 10 \\
\hline female & 21608 & 1.50 & 0.50 & 1 & 2 \\
\hline rural & 21608 & 1.64 & 0.48 & 1 & 2 \\
\hline age & 21608 & 36.27 & 14.41 & 18 & 99 \\
\hline
\end{tabular}

The education variable takes 10 values corresponding to: $0=$ No formal schooling, $1=$ Informal schooling (including Koranic schooling), 2=Some primary schooling, 3=Primary school completed, 4=Some secondary school/ High school, 5=Secondary school completed/High school, 6=Post-secondary qualifications, other than university e.g. a diploma or degree from a technical/polytechnic/college, 7=Some university, $8=$ University completed, 9=Post-graduate. 